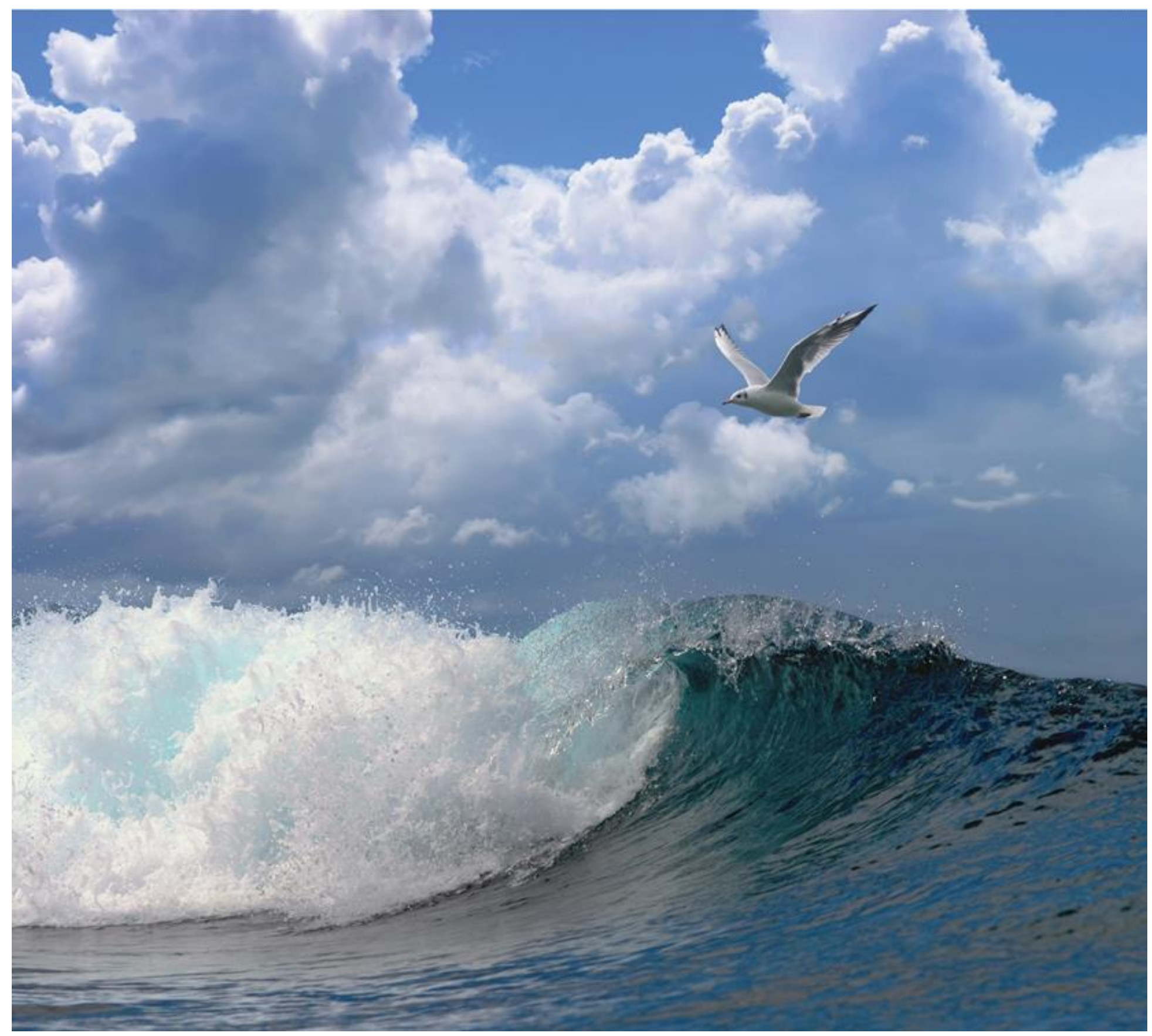

\title{
Discards survival probabilities of flatfish and rays in North Sea pulse-trawl fisheries
}




\section{Discards survival probabilities of flatfish and rays in North Sea pulse-trawl fisheries}

Author(s): $\quad$ Edward Schram and Pieke Molenaar

Publication date: 9 May 2018 
Edward Schram and Pieke Molenaar, 2018. Discards survival probabilities of flatfish and rays in North Sea pulse-trawl fisheries. Wageningen, Wageningen Marine Research (University \& Research centre), Wageningen Marine Research report C037/18. 39 pp.

Keywords: Discards survival, pulse fisheries, plaice, sole, turbot, brill, thornback ray, spotted ray, landing obligation

Client: $\quad$ Visned

Attn.: Wouter van Broekhoven

Postbus 59

$8320 \mathrm{AB}$, Urk

The Netherlands

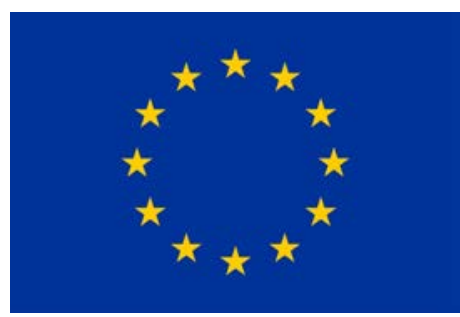

European Union, European Maritime and Fisheries Fund (EMFF)

This report can be downloaded for free from https://doi.org/10.18174/449707

Wageningen Marine Research provides no printed copies of reports

Wageningen Marine Research is ISO 9001:2008 certified.

Photo cover: Edward Schram

(C) 2016 Wageningen Marine Research Wageningen UR

Wageningen Marine Research The Management of Wageningen Marine Research is not responsible for resulting institute of Stichting Wageningen damage, as well as for damage resulting from the application of results or Research is registered in the Dutch research obtained by Wageningen Marine Research, its clients or any claims traderecord nr. 09098104, BTW nr. NL 806511618 related to the application of information found within its research. This report has been made on the request of the client and is wholly the client's property. This report may not be reproduced and/or published partially or in its entirety without the express written consent of the client. 


\section{Contents}

Preface

Summary

$1 \quad$ Introduction

$2 \quad$ Materials and Methods $\quad 7$

$\begin{array}{lll}2.1 & \text { Experimental design } & 7\end{array}$

$\begin{array}{lll}2.1 .1 & \text { Ethics statement } & 7\end{array}$

$\begin{array}{lll}2.1 .2 & \text { Outline of the experiment } & 7\end{array}$

$\begin{array}{lll}2.1 .3 & \text { Sea trips } & 7\end{array}$

$\begin{array}{lll}2.1 .4 & \text { Collection of test-fish } & 8\end{array}$

2.1.5 Control-fish 9

2.2 Assessment of fish condition and monitoring of survival 11

$\begin{array}{ll}2.3 & \text { Experimental facilities } \\ 2.41\end{array}$

$\begin{array}{lll}2.4 & \text { Data analysis } & 12\end{array}$

$\begin{array}{llr}3 & \text { Results } & 15\end{array}$

$\begin{array}{lll}3.1 & \text { Discards survival } & 15\end{array}$

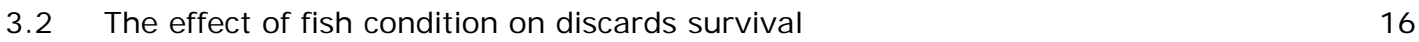

3.3 The effect of catch-processing time on discards survival probability and fish condition 18

4 Discussion $r 2$

$\begin{array}{lll}4.1 & \text { Discards survival } & 20\end{array}$

$\begin{array}{lll}4.2 & \text { Effect of fish condition on discards survival } & 22\end{array}$

4.3 Effect of catch-processing time on discards survival probability and fish condition 22

$5 \quad$ Conclusions and recommendations $\quad 24$

$\begin{array}{llr}6 & \text { Acknowledgements } & 25\end{array}$

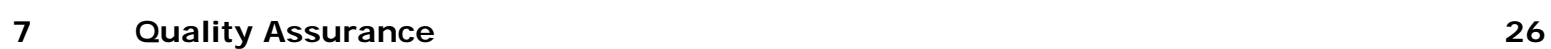

$\begin{array}{lr}\text { References } & \mathbf{2 7}\end{array}$

$\begin{array}{lr}\text { J ustification } & 28\end{array}$

$\begin{array}{lr}\text { Annex 1: Survival per trip } & 29\end{array}$

Annex 2: Frequency of vitality index scores per species and trip 38 


\section{Preface}

The project 'Survival of flatfish and ray discards' investigates four topics related to flatfish and ray discards survival in the $80 \mathrm{~mm}$ pulse-trawl fisheries in the North Sea: 1. Discards survival of plaice, sole, turbot, brill, thornback ray and spotted ray in conventional pulse-trawl fisheries, 2 . Measures to increase discards survival, 3. Factors affecting discards survival and 4. The use of vitality index scores as a proxy for discards survival.

Each topic will be reported separately and the current report is the first in the series of four reports delivered by the project.

All research data for this project were collected during nine sea trips with three commercial pulsetrawlers. Utilization of methods and research data partly overlaps among the four topics. In addition, each report can be read independently from the other reports in the series. Consequently the description of methods and reporting of data partly overlaps in the four reports.

In a later stage, parts of the results presented in these four reports will be submitted for publication in peer-reviewed scientific journals. These four reports should be considered as pre-publications of final results.

The project was commissioned by VISNED and received financial support from the European Maritime and Fisheries Fund (EMFF) of the European Union.

May, 2018. 


\section{Summary}

Discards survival probability in conventional commercial $80 \mathrm{~mm}$ pulse fisheries was assessed for undersized plaice (Pleuronectus platessa $n=558$ ), sole (Solea solea $n=274$ ), turbot (Scophthalmus maximus $n=111$ ), brill (Scophthalmus rhombus $n=90$ ), thornback ray (Raya clavata $n=99$ ) and spotted ray (Raya montagui $n=23$ ). In total nine sea trips were performed on three commercial pulsetrawlers with three trips per trawler. Sea trips were spread out over the year to account for potential seasonal variation in discards survival. All test-fish were randomly collected from the end of the sorting belt at both the start and end of the catch-sorting process from multiple hauls per sea trip. Reflex impairment and damages were assessed for all test-fish and summarized in a vitality index score indicating fish condition. Test-fish were housed in four custom-built monitoring units installed on board. Each unit contained $1624 \mathrm{~L}$ tanks. Numbers of fish housed per tank were five (plaice, sole), three (turbot, brill) and one (rays) fish per tank. Tank water was continuously renewed with sea water at a rate of at least one tank volume per hour to maintain proper water quality. Survival was monitored and dead fish were removed upon detection. Upon arrival in the vessel's home port, monitoring units were taken from board and transported to and placed in a climate controlled room to continue survival monitoring for two more weeks. The total monitoring period ranged from 15 to 18 days among test-fish depending on the day of collection at sea. In the climate controlled room, tank bottoms were covered with coarse sand and fish were fed natural food. Control-fish, fish of the same species and in good condition collected in advance at sea, were deployed during all sea trips (30-35 control plaice, 10 control sole, 3 control turbot and brill, 2 control thornback ray, 2 control spotted ray per sea trip). Control-fish were treated equally as test-fish to separate fisheries related mortality from mortality caused by the experimental procedures. Discards survival probabilities were estimated from counts of surviving fish at the end of the monitoring period.

Within all species, discards survival probabilities varied among sea trips. Discards survival probability estimates and their $95 \%$ confidence intervals $(95 \% \mathrm{Cl})$ based on all sea trips combined were $14 \%$ (95\% Cl $11-18 \%)$ for plaice, $19 \%(95 \% \mathrm{Cl} 13-28 \%)$ for sole, $30 \%(95 \% \mathrm{Cl} 20-43 \%)$ for turbot, $13 \%$ $(95 \% \mathrm{Cl} 7-23 \%)$ for brill and $53 \%(95 \% \mathrm{Cl} 40-65 \%)$ for thornback ray. For spotted ray discards survival probabilities of $21 \%$ and $67 \%$ were observed during two sea trips. Given the agreement with a previous and comparable study and the large number of observations collected year-round, we consider the current results for plaice and for sole to represent the actual overall survival probability of undersized plaice and sole discards in the $80 \mathrm{~mm}$ pulse-trawl fisheries. The discards survival probability estimates for turbot, brill and thornback ray are based on limited numbers of observations per species. These estimates should therefore be considered and treated as a first indication of the actual discards survival probability for these species in the $80 \mathrm{~mm}$ pulse-trawl fisheries. Collection of more data should narrow down the current 95\% confidence intervals and give more precise estimates for the survival probability. We expect however that these more precise estimates lie within the current $95 \%$ confidence intervals for the survival probability estimates.

In all species tested, discards survival was strongly affected by fish condition, with large differences in survival probability between fish in best and worst condition. The proportion of fish in the best condition is small and their high survival probability has little effect on the survival probability of the entire population in the catches. We therefore recommend that measures aimed at increasing discards survival focus on improving the condition of discarded fish. Since catch-processing time seems to have no effect on fish condition nor discards survival, we recommend that measures aimed at improving the condition of discarded fish focus on the fish capture process rather than catch processing. 


\section{$1 \quad$ Introduction}

Demersal pulse-trawl fisheries in the North Sea is a mixed fishery that mainly targets Dover sole (Solea solea) and plaice (pleuronectes platessa). In addition to these main target species, various bycatch species such as turbot, brill and rays are of economic importance to the fishermen as well as of ecological importance for the North Sea ecosystem. Undersized and over quota fishes and species with no market value are discarded. By 2019 this practise of discarding will be restricted for all quota regulated species by the implementation of a landing obligation under the Common Fisheries Policy (European Union, 2013). As a result of this legislation fishermen will be forced to land all undersized, damaged and marketable fish of species under quota management, also referred to as a landing obligation (LO). However, this landing obligation (LO) allows exemptions for species which according to the best available scientific advice have a high survival rate when released into the sea, taking into account gear characteristics, fishing practices and the ecosystem.

Accurate and fisheries specific estimates for discards survival probabilities are required if fisheries want to apply for high survival exemptions on the LO. Accurate estimates of discards survival probability are also required to assess the impact of exemptions on the LO in fish stock assessments.

Only one study previously assessed the survival of discards from pulse-trawl fisheries, resulting in survival probability estimates with $95 \%$ confidence intervals $(95 \% \mathrm{Cl})$ of $15 \%(95 \% \mathrm{Cl} 11-19 \%)$ for plaice, $29 \%$ (95\% Cl $24-35 \%$ ) for sole and $16 \%$ (95\% Cl 10-26\%) for dab (Van der Reijden et al., 2017). For other species that are discarded by pulse-trawl fisheries such as thornback ray, spotted ray and undersized turbot and brill, discard survival probability has never been assessed. Reliable estimates of discards survival probability for these species are thus non-existent for pulse-trawl fisheries. As a result fisheries cannot be granted an exemption under the LO based on 'high survival'. In addition, there is a clear interest amongst fishermen in survival exemptions for these species as under the LO they easily become so-called 'choke' species. As a result of the obligatory landing of undersized fish for these by-catch species, their quota may be depleted earlier in the year which forces fisheries to cease although there is still sufficient quota for the target species sole and plaice.

This study therefore aimed to provide the first estimates of discards survival probabilities in $80 \mathrm{~mm}$ pulse-trawl fisheries for turbot, brill, thornback ray and spotted ray. The survival of plaice and sole discards was assessed to strengthen the first estimates made by Van der Reijden et al. (2017). This study assessed the survival of these fish at sea during nine trips with commercial pulse-trawlers and monitored survival in captivity for 15 to 18 days. 


\section{Materials and Methods}

\section{$2.1 \quad$ Experimental design}

\subsubsection{Ethics statement}

The treatment of the fish was in accordance with the Dutch animal experimentation act, as approved by ethical committees (Experiment 2017 D0012.002)

\subsubsection{Outline of the experiment}

Discards survival in conventional pulse-trawl fisheries was assessed for undersized plaice (Pleuronectus platessa), sole (Solea solea), turbot (Scophthalmus maximus), brill (Scophthalmus rhombus), thornback ray (Raya clavata) and spotted ray (Raya montagui). The methodology was in accordance with the International Council for the Exploration of the Sea (ICES) guidelines for discards survival studies (ICES, 2016). Test-fish were collected from commercial North Sea pulse-trawl fisheries during nine sea trips. Survival was monitored for 15 to 18 days after collection of test-fish.

In addition to the assessment of discards survival in conventional pulse-trawl fisheries, measures to improve discards survival were tested for plaice and sole during the same nine sea trips in partly the same hauls. The results are reported in Molenaar and Schram (2018). When tested, measures to improve discards survival were always implemented at the vessels' starboard side gears and hoppers. For these hauls, test-fish for conventional pulse-trawl fisheries were consequently collected from the port side gears. This applies for all sea trips to plaice and for three sea trips for sole (see 2.1.3).

\subsubsection{Sea trips}

All test-fish were collected during nine sea trips on three commercial pulse-trawlers with three trips per trawler. Sea trips were spread out over the year (Table 1) to account for the potential effect of variable environmental and fishing conditions on discards survival (Van der Reijden et al., 2017). The typical number of hauls was 40 to 50 per sea trip. All fishery operations were conducted in the Southern North Sea according to conventional, regular commercial practices of the pulse-trawlers. Sea trips typically started on Mondays around 0:00 and ended on Fridays around 4:00. For each haul during a sea trip operational and environmental conditions were recorded. Conditions during the sea trips are presented in Table 1. Vessel and gear specifics are presented in Table 2 and locations of sampled hauls in Figure 1.

Table 1. Conditions during the sea trips

\begin{tabular}{|c|c|c|c|c|c|c|c|c|c|c|c|}
\hline Trip & Vessel & Year & Month & Week & \multicolumn{2}{|c|}{$\begin{array}{c}\text { Temperature } \\
\left({ }^{\circ} \mathrm{C}\right)\end{array}$} & $\begin{array}{c}\text { Wind } \\
\text { speed } \\
(\text { Bft })\end{array}$ & $\begin{array}{c}\text { Wave } \\
\text { height } \\
(\mathrm{m})\end{array}$ & $\begin{array}{c}\text { Catch } \\
\text { processing } \\
(\mathrm{min})\end{array}$ & $\begin{array}{c}\text { Haul } \\
\text { duration } \\
(\mathrm{min})\end{array}$ & $\begin{array}{c}\text { Fishing } \\
\text { depth } \\
(\mathrm{m})\end{array}$ \\
\hline 1 & 1 & 2017 & May & 18 & - & $9-12$ & $2-5$ & $0.5-2.0$ & 30 & $110-135$ & $18-28$ \\
\hline 2 & 2 & 2017 & May & 21 & $14-19$ & $12-13$ & $0-4$ & $0.2-0.5$ & 24 & 120 & $30-50$ \\
\hline 3 & 3 & 2017 & June & 24 & $15-20$ & $14-15$ & $1-5$ & $0.1-1.5$ & 20 & $110-125$ & $22-24$ \\
\hline 4 & 3 & 2017 & July & 28 & $15-21$ & $16-17$ & $1-6$ & $0.1-1.0$ & 23 & $110-120$ & $25-40$ \\
\hline 5 & 1 & 2017 & Sept & 36 & $15-18$ & 18 & $4-5$ & $0.5-1.5$ & 26 & $120-145$ & $26-37$ \\
\hline 6 & 3 & 2017 & Oct & 44 & $12-15$ & $13-15$ & $3-5$ & $0.5-2.0$ & 20 & $110-130$ & $27-34$ \\
\hline 7 & 2 & 2017 & Dec & 49 & $5-9$ & $11-12$ & $3-5$ & $1-0-2.0$ & 34 & 120 & $35-50$ \\
\hline 8 & 1 & 2018 & Jan & 4 & $7-10$ & $6-7$ & $5-6$ & $0.5-2.6$ & 33 & 120 & $28-39$ \\
\hline 9 & 2 & 2018 & Feb & 8 & $4-8$ & $7-8$ & $2-5$ & $0.5-1.5$ & 25 & $110-120$ & $22-52$ \\
\hline
\end{tabular}




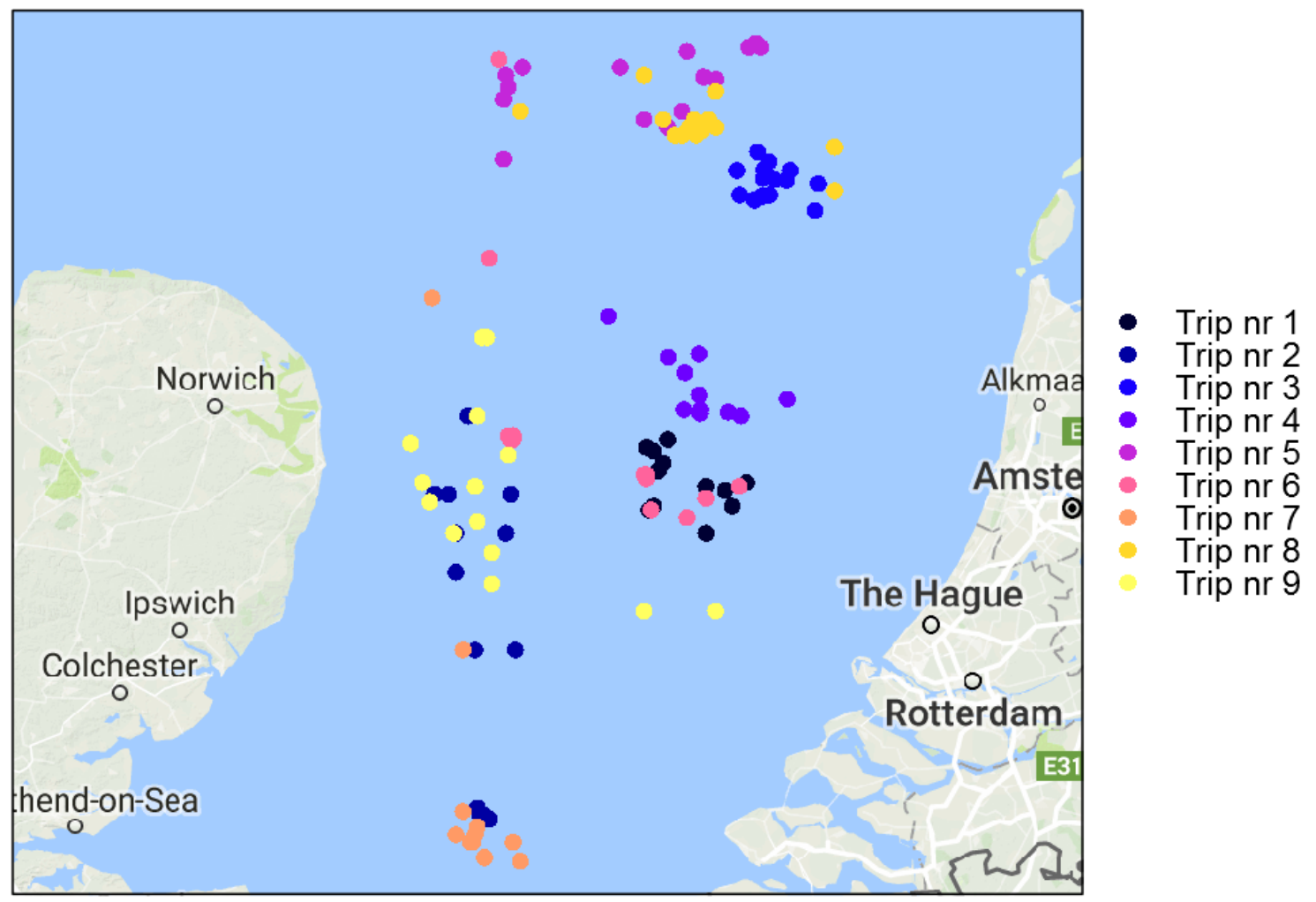

Figure 1. Locations of sampled hauls per sea trip

\subsubsection{Collection of test-fish}

Test-fish were collected during regular, semi-automatic catch-processing (Figure 2). In this process, catches are discharged from the cod-ends into a hopper (one hopper for each of the two cod-ends). From the hoppers, the catches are discharged into a central pit (not shown in Figure 2) from which the catch is transported by a conveyer belt onto the sorting belt. Marketable fish are manually collected from the sorting belt by the vessel's crew. At the end of the sorting belt, the remaining catch, including fish that are discarded, drops into a gutter that discharges back into the sea. All test-fish were randomly collected from the end of the sorting belt just before discarding (Figure 2).

Within each sea trip, fish were collected from multiple hauls to account for potential variation in fishing conditions and discards survival among hauls. To obtain representative samples from hauls and account for the potential effects of processing time on discards survival (Benoit et al., 2013), fish were collected as much as possible in equal numbers at both the start and the end of the catch-sorting process of each haul. For each sampled haul, the time at which catches were discharged in the hoppers and the subsequent times individual fish were collected, were recorded to determine catchprocessing time of individual fish.

During all nine sea trips, plaice were collected from six hauls per trip from the catches discharged in the port side hopper (since treatments to improve discards survival were applied to the starboard side hopper, see 2.2.1). For this purpose the catches in both hoppers were processed separately and appeared as two separate batches on the sorting belt. For these six hauls the processing sequence of the two hoppers was alternated between hauls to obtain an equal average catch-processing time across the collected test-fish. Plaice were consequently collected from three hauls that appeared first on the sorting belt and three hauls that appeared last on the sorting belt. For each haul 10 test-fish were randomly collected from the end of the sorting belt just before discarding, 5 at the start and 5 at the end of the catch-sorting process. This results in the collection of circa 60 test-fish per sea trip, 
except for sea trips number 5 in which 80 test-fish were collected. In total 558 test-fish were collected for plaice (Table 4, page 14).

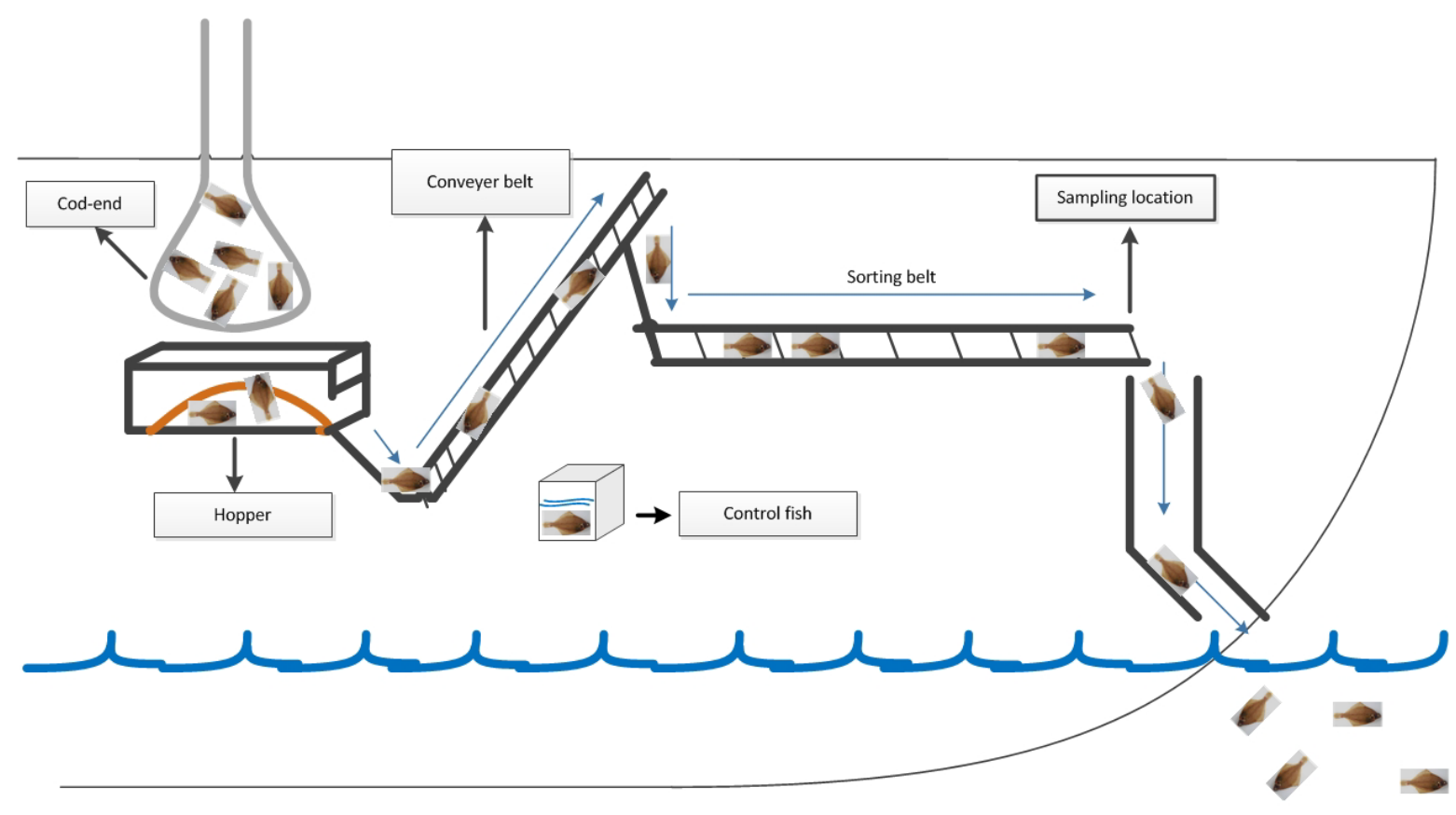

Figure 2. Schematic drawing of semi-automatic catch processing line on board of a pulse trawler. All fish collected from the catch for the survival experiment are collected at the location marked with 'sample location'.

Sole were collected during all nine sea trips. During six out of nine sea trips, sole were collected from three hauls for which the catches in the hoppers were processed together. During those trips 10 testfish per haul were collected at the end of the sorting belt, 5 from the start and 5 at the end of the catch-sorting process. During the other three sea trips (5, 6 and 7$)$, measures to improve sole discards survival were tested (see 2.2.1) and test-fish for the conventional pulse-trawl fisheries were consequently collected from the port side hopper only. The order in which the hoppers were processed was alternated. For these three trips, 15 test-fish per haul were collected, alternating between hauls 7 or 8 at the start and end of the catch-sorting process. Both sampling procedures resulted in the collection 30 test-fish per sea trip and 270 test-fish for the entire experiment for sole.

By-catch species turbot, brill, thornback ray and spotted ray were collected from two to seven hauls per sea trip, depending on their availability in the catches. For these hauls the catches in the hoppers were processed at the same time and thus appeared as a single mixed batch on the sorting belt. For these species the number of undersized fish was limited in some of the sampled hauls. As a result it was not always possible to collect sufficient or equal numbers of test-fish strictly at the start and end of the catch-sorting process. Test-fish were in this case also collected during the entire catch sorting process.

During some sea trips mortalities among test-fish resulted in empty tanks in the monitoring units which were then utilized to collect additional test-fish. The numbers of test-fish collected per species and sea trips are presented in Table 4 (page 14).

\subsubsection{Control-fish}

In each of the nine sea trips and for each species tested, control-fish of the same species were deployed to separate potential effects of the experimental procedures on mortality from fisheriesinduced mortality. Before each of the nine sea trips, control-fish were transported from the research facilities to the vessel and taken on-board of the pulse-trawler. At the vessel control-fish were stored on deck in aerated 600L tanks with regularly renewed surface seawater. Only fish in visually observed good condition, well-fed and without visible injuries, were selected for use as control-fish. Control-fish 
were exposed to the exact same experimental procedures as the test-fish, including vitality assessment, tagging and housing in the monitoring units throughout the experiments. The number of control-fish deployed was approximately $30 \%$ of the number of test-fish per species (Table 4 , page 14). Control-fish were obtained by commercial shrimp and pulse beam trawlers $(<221 \mathrm{~kW})$ which had been requested to collect least damaged and undersized fish from short hauls. Control-fish were also collected during the sea trips with the pulse-trawlers for use in subsequent sea trips. In both cases collected fish were stored on-board in $600 \mathrm{~L}$ containers filled with surface seawater which was aerated and regularly exchanged to maintain proper water quality. Prior to their use, control-fish were stored in tanks placed in a climate controlled room for at least three weeks. During this period, fisheriesinduced mortality levelled out while surviving fish could recover from injuries and regain good condition. Tanks with candidate control-fish were inspected daily for mortalities which were removed upon detection. During storage, fish were fed daily with live polychaete worms (Nereis spp) and dead, uncooked brown shrimps (Crangon crangon) to visually observed satiation.

Table 2. Vessel and gear specifics

\begin{tabular}{|c|c|c|c|c|}
\hline \multicolumn{2}{|l|}{ Specifics } & Vessel 1 & Vessel 2 & Vessel 3 \\
\hline \multirow[t]{4}{*}{ Vessel } & Engine power $(\mathrm{Kw})$ & 1471 & 1430 & 1470 \\
\hline & Gear & Sumwing pulse & Sumwing pulse & Sumwing pulse \\
\hline & Number of gears & 2 & 2 & 2 \\
\hline & Fishing speed (kn) & 4.8 & 4.8 & 4.9 \\
\hline \multirow[t]{3}{*}{ Beam (wing) } & Width $(\mathrm{m})$ & 12 & 12 & 12 \\
\hline & Length $(\mathrm{m})$ & 1.1 & 1.1 & 1.1 \\
\hline & Total weight $(\mathrm{kg})$ & 2600 & 2740 & 2300 \\
\hline \multirow[t]{4}{*}{ False ground rope } & Type & Rubber discs & Rubber discs & Rubber discs \\
\hline & Length $(\mathrm{m})$ & 11.7 & 11 & 11.8 \\
\hline & Diameter $(\mathrm{mm})$ & 220 & 120 & 120 \\
\hline & Total weight $(\mathrm{kg})$ & 110 & 140 & 80 \\
\hline \multirow[t]{5}{*}{ Electrodes } & Number & 22 & 24 & 26 \\
\hline & Type & HFK & HFK & HFK \\
\hline & Total length $(\mathrm{m})$ & 7.5 & 7.2 & 7.4 \\
\hline & $\begin{array}{l}\text { Distance between } \\
\text { electrodes }(\mathrm{cm})\end{array}$ & 40.0 & 42.5 & 45.0 \\
\hline & $\begin{array}{l}\text { Length electrodes } \\
\text { on seabed (pulse } \\
\text { field) }(\mathrm{m})\end{array}$ & 3.0 & 3.2 & 4.4 \\
\hline \multirow{4}{*}{$\begin{array}{l}\text { Conductor } \\
\text { elements }\end{array}$} & Number & 11 & 10 & 12 \\
\hline & Diameter (mm) & 35 & 28 & 33 \\
\hline & Length $(\mathrm{mm})$ & 130 & 130 & 134 \\
\hline & $\begin{array}{l}\text { Distance between } \\
\text { elements }(\mathrm{mm})\end{array}$ & 220 & 210 & 200 \\
\hline \multirow[t]{5}{*}{ Pulse } & Power $(\mathrm{kW} / \mathrm{m})$ & 6.0 & 5.3 & 7.3 \\
\hline & Width ( $\mu s)$ & 340 & 390 & 330 \\
\hline & Frequency $(\mathrm{Hz})$ & 60 & 45 & 60 \\
\hline & $\begin{array}{l}\text { Peak voltage over } \\
\text { electrode }(\mathrm{V})\end{array}$ & 60 & 60 & 60 \\
\hline & $\begin{array}{l}\text { Maximum exposure } \\
\text { to pulse field (s) }\end{array}$ & 1.2 & 1.3 & 1.7 \\
\hline \multirow[t]{4}{*}{ Trawl } & Total length (m) & 34 & 30 & 34 \\
\hline & $\begin{array}{l}\text { Mesh size cod-end } \\
(\mathrm{mm})\end{array}$ & 80 & 80 & 80 \\
\hline & Twine cod-end & Double knotted & Double knotted & Double knotted \\
\hline & $\begin{array}{l}\text { Twine thickness } \\
(\mathrm{mm})\end{array}$ & 4 & 3 & 3 \\
\hline
\end{tabular}




\subsection{Assessment of fish condition and monitoring of survival}

After collection from the sorting belt, test-fish were temporarily stored in $105 \mathrm{~L}$ holding containers filled with seawater. The seawater in the holding containers was regularly renewed to maintain sufficient dissolved oxygen levels during storage. Upon completion of fish collection, fish were sequentially taken from the temporary holding containers to measure total length (TL: in cm below) and for vitality assessment and tagging. Fish were taken randomly from the holding containers in case more than the required number of fish had been collected. Vitality status of each individual fish was assessed by scoring vitality class, external damage and reflex impairment as described by Van der Reijden et al. (2017) and summarized in Table 3 (page 13). For thornback and spotted ray the protocols for external damage and reflex impairment scores in flatfish by Van der Reijden et al. (2017) were adapted (Table 3).

Individual fish were tagged with Trovan Unique glass transponders (type ID100) to allow for identification of individuals throughout the experiments. Transponders were injected subcutaneously just behind the head using the IIDI00E injector. Upon completion of the vitality assessment and tagging, live fish were placed in $24 \mathrm{~L}$ tanks (see Experimental facilities) with a maximum of five (plaice and sole), three (turbot and brill), one or two small $(<35 \mathrm{~cm})$ individuals (spotted rays) or one (thornback ray) fish per tank. Fish that were dead (defined as the absence of gill plate/spiracle movement in water and head-complex for more than 15 seconds, Table 3) at the moment of vitality assessment were recorded as dead at time zero. Dead fish were stored on ice and not replaced by live individuals.

Monitoring of survival and experimental conditions started after the first fish had been placed in the monitoring units. All tanks containing fish were inspected every 12 hours on-board and every 24 hours after transfer to the laboratory. Tanks were inspected for mortalities through or by lifting the transparent lid of the tanks by visual observation of fish movement. In case any mortalities were suspected to be present, these individuals were gently touched with a blunt plastic probe to provoke a behavioural response. Fish that showed no response were manually removed from the tank and dead was confirmed by visual observation of a 15 seconds absence of gill plate/spiracle movement in water and the 'head complex' reflex (Table 3). Lethargic fish were not removed. Dissolved oxygen concentration and saturation and water temperature were measured (Hach Lange Multimeter). Water flows to the individual tanks were increased if oxygen saturation was below $80 \%$.

\subsection{Experimental facilities}

All test-fish collected during sea trips and control-fish were housed in four custom-built monitoring units installed on-board of the vessels. Each unit consisted of a stainless steel framework which holds $1624 \mathrm{~L}$ tanks $(60 \mathrm{~cm} \mathrm{~L} \times 40 \mathrm{~cm} \mathrm{~W} \times 12 \mathrm{~cm} \mathrm{H}$ ), resulting in a total capacity of 64 tanks on a vessel. Each tank was equipped with an individual water supply. A central pump installed on the vessel continuously supplied surface seawater to the tanks. The water intake of this pump was approximately 2 meters below sea surface. Water flow rates to the tanks were installed at approximately two tank volumes per hour (1-1.5 $\mathrm{L}^{-1} \mathrm{~min}$ ) to maintain proper water quality. Tanks were covered with transparent lids to limit water losses by sloshing while allowing for visual inspection of the fish. Upon return of the vessels in their home ports, the entire units were off-loaded and transported to the laboratory by road in a temperature controlled truck. Transport time ranged from one to three hours depending on the home port of the vessel. During transport each unit was placed inside a pumping tank partly filled with seawater and equipped with a submerged pump to supply water to each fish tank in the unit. Fish tanks discharged their effluents in the pumping tank, allowing for recirculation and aeration of the water. Upon arrival at the laboratory the fish tanks containing plaice and sole were manually stacked in racks. Turbot and brill were, grouped by species, stocked in tanks with a bottom surface area of $1 \mathrm{~m}^{2}$. Rays were stocked in tanks of $2 \mathrm{~m}^{2}$. All tanks were connected to a single water recirculation system consisting of a $440 \mathrm{~L}$ pumping tank and a $330 \mathrm{~L}$ trickling filter. Total system volume was approximately $3.2 \mathrm{~m}^{3}$ and continuously renewed with filtered water from the Eastern 
Scheldt at a rate of $8.6 \mathrm{~m}^{3} / \mathrm{d}$. All tanks were placed in a temperature controlled room with its temperature set at the actual North Sea surface water temperature at the time of test-fish collection. In the laboratory, all tanks were supplied with coarse sand as bottom substrate and the fish were fed daily to visually observed satiation with polychaete worms (Nereis spp) and uncooked brown shrimps (Crangon crangon). On-board, bottom substrate was not applied as in combination with the inevitable rocking of the vessels, sand would probably result in injuries through abrasion of the fish. Fish were not fed on-board as in our experience from previous discards survival studies they do not restart feeding until several days after catching while uneaten feed in the tanks would compromise water quality.

\subsection{Data analysis}

Survival, fish condition and sampling related time data were collected at the level of the individual fish. Fish were either dead or alive at the end of the survival monitoring period. Survival probabilities per treatment were estimated and tested for significant differences by multilevel linear logistic regression with sea trips, hauls and individual fish as subsequent levels. The resulting estimates and $95 \%$ confidence intervals for the odds ratios were back transformed in survival percentages per species. To account for imbalances in the number of observations per sea trip and to give sea trips equal weight in the analysis, the contribution of each individual fish was weighed according to the number of test-fish collected per sea trip.

For each fish that died during the course of survival monitoring, the survival time was recorded as the time (h) since collection from the catch. Survival curves presenting the development over time of survival within a group, were estimated using the non-parametric Kaplan-Meier estimator (Kaplan and Meier, 2012).

Discards survival per species was tested for differences among sea trips 1 to 9 by comparing the counts of dead and alive fish at the end of the survival monitoring in each sea trip using Chi-square when counts per grouping were $>5$. In all other cases, Fisher's exact test was used.

Fish condition of individual fish was expressed using a vitality index score with classes A, B, C and D (Table 3, page 13). Fish condition of a group of fish was expressed as the frequency of individual vitality index scores within the group. Per species, the survival probabilities per vitality index score was estimated and tested for significant differences by multilevel linear logistic regression with sea trips, hauls and individual fish as subsequent levels. Sea trips were given equal weight in the analysis. The resulting estimates and $95 \%$ confidence intervals for the odds ratios were back transformed in survival percentages per vitality index score class. A least significance difference (LSD) post-hoc analysis was used to estimate the level of significance between vitality index score classes in case a significant effect was detected for a species.

Catch-processing time was calculated for each individual test-fish as the time difference between discharging the catch in the hoppers and collection from the sorting belt. The effect of catchprocessing time on discards survival probability was tested per species using a binary mixed model with the continuous variable catch-processing time as fixed effect and the class variables sea trip and haul, nested in sea trip, as random effects.

The effect of catch-processing time on class variable vitality index score was tested per species by comparing mean values for the catch-processing times among vitality index score classes. For this test a linear mixed model (REML) with vitality class index as fixed effect and sea trip and haul, nested in sea trip, as random effects. A least significance difference (LSD) post-hoc analysis was used to estimate the level of significance between vitality index score classes in case a significant effect was detected for a species. In all cases the fiducial limit was set at $5 \%$. 
Table 3. Description of criteria to score vitality status (after Van der Reijden et al. (2017)).

\begin{tabular}{|c|c|}
\hline \multicolumn{2}{|c|}{ Vitality index - All species } \\
\hline Class & Description \\
\hline A & Fish lively, no visible signs of loss of scale or mucus layer. \\
\hline B & $\begin{array}{l}\text { Fish less lively, minor lesions and some scales missing, mucus layer } \\
\text { affected up to } 20 \% \text { of skin surface area, some point haemorrhaging on the } \\
\text { blind side. }\end{array}$ \\
\hline C & $\begin{array}{l}\text { Fish lethargic, intermediate lesions and some patches without scales, } \\
\text { mucus layer affected up to } 50 \% \text { of skin surface area, several point } \\
\text { haemorrhaging on the blind side. }\end{array}$ \\
\hline $\mathrm{D}$ & $\begin{array}{l}\text { Fish lethargic or dead, clear head haemorrhaging, major lesions and } \\
\text { patches without scales, mucus layer affected for more than } 50 \% \text { of the skin } \\
\text { surface area, significant point haemorrhaging on the blind side. }\end{array}$ \\
\hline \multicolumn{2}{|c|}{$\begin{array}{l}\text { Damage scores - All species (Damages marked with * were not scored for Thornback an Spotted } \\
\text { rays, ** was not scored for thornback rays) }\end{array}$} \\
\hline Damage & Description ( 1 = present; $0=$ absent $)$ \\
\hline Fin or wings & Fins are damaged or split (including tail fin). Wings in case of rays. \\
\hline$>50 \% * *$ & $\begin{array}{l}\text { Damage to skin surface, scale or mucus layer at more than } 50 \% \text { of the } \\
\text { dorsal body surface. }\end{array}$ \\
\hline Head haemorrhages* & Presence of a haemorrhage in the head of the fish \\
\hline $\begin{array}{l}\text { Hypodermic } \\
\text { haemorrhages }\end{array}$ & Presence of a hypodermic haemorrhage \\
\hline Intestines & $\begin{array}{l}\text { Intestines are protruding or are visible through damaged body tissue of the } \\
\text { fish. }\end{array}$ \\
\hline Wound & Presence of a wound such that flesh is visible. \\
\hline \multicolumn{2}{|c|}{ Reflex impairment scores - Plaice, sole, turbot and Brill } \\
\hline Reflex & $\begin{array}{l}\text { Description ( } 1 \text { = impaired; no (clear) response within } 5 \text { s of observation; } 0 \\
=\text { unimpaired; obvious response within } 5 \mathrm{~s} \text { ). }\end{array}$ \\
\hline Body flex & $\begin{array}{l}\text { Fish is held out of the water on the palm of the hand with its ventral side } \\
\text { up. Fish actively tries to move head and tail towards each other or wriggle } \\
\text { out of the hand. }\end{array}$ \\
\hline Righting & $\begin{array}{l}\text { Fish is held on the fingers of two hands with the dorsal side touching the } \\
\text { water surface. When released the fish actively rights itself under water. }\end{array}$ \\
\hline Evasion & $\begin{array}{l}\text { Fish is held underwater in an upright position by supporting its ventral side } \\
\text { with the fingers and its dorsal side with the thumbs. When the thumbs are } \\
\text { lifted the fish actively swims away. }\end{array}$ \\
\hline Stabilize & $\begin{array}{l}\text { Untouched fish tries to find a stable position flat on the bottom by rhythmic } \\
\text { and swift movement of the fins and/or body. }\end{array}$ \\
\hline Tail grab & $\begin{array}{l}\text { Fish is gently held by the tailfin between the thumb and index finger. Fish } \\
\text { actively struggles free and swims away. }\end{array}$ \\
\hline Head complex & $\begin{array}{l}\text { Fish moves its operculum or mouth during } 5 \mathrm{~s} \text { of observation while laying } \\
\text { undisturbed under water. }\end{array}$ \\
\hline \multicolumn{2}{|c|}{ Reflex impairment scores - Thornback ray and Spotted ray } \\
\hline Reflex & $\begin{array}{l}\text { Description ( } 1 \text { = impaired; no (clear) response within } 5 \text { s of observation; } 0 \\
=\text { unimpaired; obvious response within } 5 \mathrm{~s} \text { ). }\end{array}$ \\
\hline Wings & $\begin{array}{l}\text { Ray is held out of the water, dorsal side up with one hand supporting the } \\
\text { body at the head of the ray and the other hand supporting the body at the } \\
\text { base of the tail. The ray actively flaps its pectoral fins (wings). }\end{array}$ \\
\hline Eye retraction & $\begin{array}{l}\text { While in the water the ray is gently tapped on the head just behind the } \\
\text { eyes with a blunt probe. The ray actively retracts its eyes. }\end{array}$ \\
\hline Stabilize & $\begin{array}{l}\text { While resting on the bottom, the ray is gently held by the tail. When the tail } \\
\text { is lifted, the observer notices more resistance than caused by the weight of } \\
\text { the ray; as if the ray sucks its body to the bottom of the tank. }\end{array}$ \\
\hline Tail grab & $\begin{array}{l}\text { While resting on the bottom the ray is gently held by the tail. When the tail } \\
\text { is gently pulled backwards, the ray struggles free and swims away. }\end{array}$ \\
\hline
\end{tabular}


Table 4. Numbers of test-fish collected from the start, end and during (Mid) catch-sorting processes and the number control-fish deployed per species and sea trip.

\begin{tabular}{|c|c|c|c|c|c|c|c|c|c|c|c|c|c|c|c|c|c|c|c|c|c|c|c|c|c|c|c|c|c|}
\hline \multirow{3}{*}{ Trip } & \multicolumn{4}{|c|}{ Plaice } & \multicolumn{5}{|c|}{ Sole } & \multicolumn{5}{|c|}{ Turbot } & \multicolumn{5}{|c|}{ Brill } & \multicolumn{5}{|c|}{ Thornback ray } & \multicolumn{5}{|c|}{ Spotted ray } \\
\hline & \multicolumn{3}{|c|}{ Test-fish } & \multirow[t]{2}{*}{ Control } & \multicolumn{4}{|c|}{ Test-fish } & \multirow[t]{2}{*}{ Control } & \multicolumn{4}{|c|}{ Test-fish } & \multirow[t]{2}{*}{ Control } & \multicolumn{4}{|c|}{ Test-fish } & \multirow[t]{2}{*}{ Control } & \multicolumn{4}{|c|}{ Test-fish } & \multirow[t]{2}{*}{ Control } & \multicolumn{4}{|c|}{ Test-fish } & \multirow[t]{2}{*}{ Contro } \\
\hline & Start & End & Total & & Start & Mid & End & Total & & Start & Mid & End & Total & & Start & Mid & End & Total & & Start & Mid & End & Tota & & Start & Mid & End & Total & \\
\hline 1 & 30 & 30 & 60 & 35 & 15 & - & 16 & 31 & 10 & 5 & - & 4 & 9 & 3 & 5 & - & 4 & 9 & 2 & - & 9 & 1 & 10 & 2 & - & - & - & - & - \\
\hline 2 & 30 & 30 & 60 & 30 & 15 & - & 15 & 30 & 10 & 4 & 5 & 2 & 11 & 3 & 6 & 3 & 3 & 12 & 3 & 3 & - & 8 & 11 & 2 & - & - & - & - & - \\
\hline 3 & 32 & 28 & 60 & 30 & 15 & - & 15 & 30 & 8 & - & 15 & - & 15 & 3 & - & 15 & - & 15 & 3 & - & 9 & - & 9 & 2 & - & - & - & - & - \\
\hline 4 & 30 & 29 & 59 & 30 & 15 & - & 15 & 30 & 10 & 1 & 4 & 3 & 8 & 3 & 2 & 7 & - & 9 & 3 & 3 & 5 & 1 & 9 & 2 & - & - & - & - & - \\
\hline 5 & 40 & 40 & 80 & 33 & - & 33 & - & 33 & 10 & 15 & - & 16 & 31 & 3 & 5 & - & 4 & 9 & 3 & 7 & - & 7 & 14 & 2 & - & - & - & - & - \\
\hline 6 & 30 & 30 & 60 & 30 & 15 & & 15 & 30 & 15 & 3 & 5 & 4 & 12 & 3 & 3 & 4 & 2 & 9 & 3 & 3 & 8 & 3 & 14 & 2 & - & - & - & - & - \\
\hline 7 & 30 & 30 & 60 & 30 & 15 & - & 15 & 30 & 15 & - & 9 & - & 9 & 3 & - & 8 & - & 8 & 3 & - & 9 & - & 9 & 2 & - & - & - & - & - \\
\hline 8 & 30 & 30 & 60 & 30 & 15 & - & 15 & 30 & 10 & 3 & 3 & 3 & 9 & 3 & 4 & 4 & 2 & 10 & 3 & 2 & 6 & 6 & 10 & 2 & 7 & 3 & 4 & 14 & 2 \\
\hline 9 & 29 & 30 & 59 & 29 & 15 & - & 15 & 30 & 10 & 4 & - & 3 & 7 & 3 & 1 & 6 & 2 & 9 & 3 & 7 & - & 2 & 9 & 2 & 5 & - & 4 & 9 & 2 \\
\hline Total & 281 & 277 & 558 & 277 & 120 & 33 & 121 & 274 & 98 & 35 & 41 & 35 & 111 & 27 & 26 & 47 & 17 & 90 & 26 & 25 & 46 & 28 & 99 & 18 & 12 & 3 & 8 & 23 & 4 \\
\hline
\end{tabular}

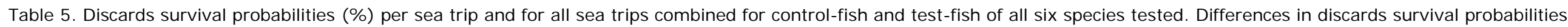
among sea trips were detected within all species except brill and spotted ray $\left(\mathrm{X}^{2}\right.$ or Fisher's exact test $\left.{ }^{(*)}\right)$.

\begin{tabular}{|c|c|c|c|c|c|c|c|c|c|c|c|c|c|c|c|c|}
\hline \multirow{2}{*}{\begin{tabular}{|ll} 
& Trip \\
& \\
& \\
\end{tabular}} & \multirow{2}{*}{$\begin{array}{c}\text { Vessel } \\
1 \\
\end{array}$} & \multirow{2}{*}{\begin{tabular}{|l} 
Year \\
2017 \\
\end{tabular}} & \multirow{2}{*}{$\begin{array}{l}\text { Month } \\
\text { May } \\
\end{array}$} & \multirow{2}{*}{$\begin{array}{c}\text { Week } \\
18 \\
\end{array}$} & \multicolumn{2}{|c|}{$\begin{array}{c}\text { Plaice } \\
\text { \# Test \#Control }\end{array}$} & \multicolumn{2}{|c|}{$\begin{array}{c}\text { Sole } \\
\text { \# Test \#Control }\end{array}$} & \multicolumn{2}{|c|}{$\begin{array}{l}\text { Turbot } \\
\text { \# Test \#Control }\end{array}$} & \multicolumn{2}{|c|}{$\begin{array}{c}\text { Brill } \\
\text { \# Test \#Control }\end{array}$} & \multicolumn{2}{|c|}{$\begin{array}{l}\text { Thornback ray } \\
\text { \# Test \#Control }\end{array}$} & \multicolumn{2}{|c|}{$\begin{array}{l}\text { Spotted ray } \\
\text { \# Test \#Contro }\end{array}$} \\
\hline & & & & & $15 \%$ & $100 \%$ & $45 \%$ & $100 \%$ & $44 \%$ & $100 \%$ & $33 \%$ & $100 \%$ & $40 \%$ & $100 \%$ & - & - \\
\hline 2 & 2 & 2017 & May & 21 & $15 \%$ & $97 \%$ & $50 \%$ & $100 \%$ & $55 \%$ & $100 \%$ & $\mathbf{2 5 \%}$ & $100 \%$ & $82 \%$ & $100 \%$ & - & - \\
\hline 3 & 3 & 2017 & June & 24 & $12 \%$ & $100 \%$ & $40 \%$ & $100 \%$ & $40 \%$ & $100 \%$ & $7 \%$ & $100 \%$ & $63 \%$ & $100 \%$ & - & - \\
\hline 4 & 3 & 2017 & July & 28 & $3 \%$ & $90 \%$ & $23 \%$ & $100 \%$ & $63 \%$ & $100 \%$ & $\mathbf{0} \%$ & $100 \%$ & $56 \%$ & $100 \%$ & - & - \\
\hline 5 & 1 & 2017 & Sept & 36 & $1 \%$ & $30 \%$ & $3 \%$ & $90 \%$ & $17 \%$ & $100 \%$ & $\mathbf{0} \%$ & $100 \%$ & $57 \%$ & $100 \%$ & - & - \\
\hline 8 & 1 & 2018 & Jan & 4 & $17 \%$ & $72 \%$ & $0 \%$ & $100 \%$ & $\mathbf{0} \%$ & $100 \%$ & $10 \%$ & $67 \%$ & $\mathbf{0} \%$ & $50 \%$ & $21 \%$ & $100 \%$ \\
\hline 9 & 2 & 2018 & Feb & 8 & $20 \%$ & $93 \%$ & $3 \%$ & $100 \%$ & $\mathbf{0} \%$ & $100 \%$ & $11 \%$ & $67 \%$ & $56 \%$ & $100 \%$ & $67 \%$ & $100 \%$ \\
\hline \multicolumn{5}{|c|}{$\mathrm{p}$-value $\mathrm{X}^{2}$ or Fisher's exact test ${ }^{(*)}$} & 0.002 & - & $<0.001$ & - & $0.02^{*}$ & - & $0.14^{*}$ & - & $0.01^{*}$ & - & - & - \\
\hline \multicolumn{5}{|l|}{ Overall } & $14 \%$ & $84 \%$ & $19 \%$ & $99 \%$ & $30 \%$ & $100 \%$ & $13 \%$ & $93 \%$ & $53 \%$ & $94 \%$ & $44 \%$ & $100 \%$ \\
\hline
\end{tabular}

14 of 39 | Wageningen Marine Research report Fout! Verwijzingsbron niet gevonden. 


\section{Results}

\subsection{Discards survival}

The estimates for the overall discards survival and their $95 \%$ confidence intervals are presented per species in Table 6. For spotted ray no estimate for its overall discards survival is given because this species was collected during two trips only. Discards survival per sea trip is presented per species in Table 5 (page 14). Clearly discards survival varies among sea trips with significant differences among sea trips for all species except brill ( $X^{2}$ or Fisher's exact test $p<0.05$, Table 5 ).

Table 6. Overall discards survival probability per species.

\begin{tabular}{|c|c|c|c|}
\hline \multirow[t]{2}{*}{ Species } & \multicolumn{3}{|c|}{ Overall discards survival probability (\%) } \\
\hline & Estimate & $95 \% \mathrm{Cl} \mathrm{LL}$ & $95 \% \mathrm{Cl}$ UL \\
\hline Plaice & $14 \%$ & $11 \%$ & $18 \%$ \\
\hline Sole & $19 \%$ & $13 \%$ & $28 \%$ \\
\hline Turbot & $30 \%$ & $20 \%$ & $43 \%$ \\
\hline Brill & $13 \%$ & $7 \%$ & $23 \%$ \\
\hline Thornback ray & $53 \%$ & $40 \%$ & $65 \%$ \\
\hline
\end{tabular}

The development over time of the survival of discards after collection at sea is presented per species in Figure 3 for all nine sea trips separately (a) and all sea trips combined (b). For the flatfish species mortality is high in the first five days after collection. After day five, survival stabilizes with incidental mortalities. Survival over time of thornback, spotted ray and to some extent turbot shows a different pattern. Initial mortality rates for the rays are lower than observed for the flat fishes but mortality continues up to around ten to fifteen days after collection of test-fish. The survival monitoring periods of 15 to 18 days were of sufficient duration as mortality levelled out in all cases before survival monitoring was terminated.

Survival of turbot control-fish was $100 \%$ in all sea trips. For sole control-fish survival was $100 \%$ in all trips except for trip 5 in which $90 \%$ of the control-fish survived. Survival of brill control-fish was $100 \%$ in all trips except for trips 8 and 9. In both these trips one out of the three control-fish died, resulting in a survival of $67 \%$ among control-fish. Survival of thornback ray control-fish was $100 \%$ in all trips except trip 8 in which one out of the two control-fish died, resulting in 50\% survival among controlfish. Survival of spotted ray control-fish was $100 \%$ in both sea trips in which this species was tested. Survival of plaice control-fish was over $90 \%$ in six of the nine sea trips. In two trips the survival of plaice control-fish was $72 \%$ and in one trip it was $30 \%$ (Table 5 , page 14 ). Control-fish survival over all nine sea trips was $84 \%$ for plaice and $>90 \%$ for all other species tested. 

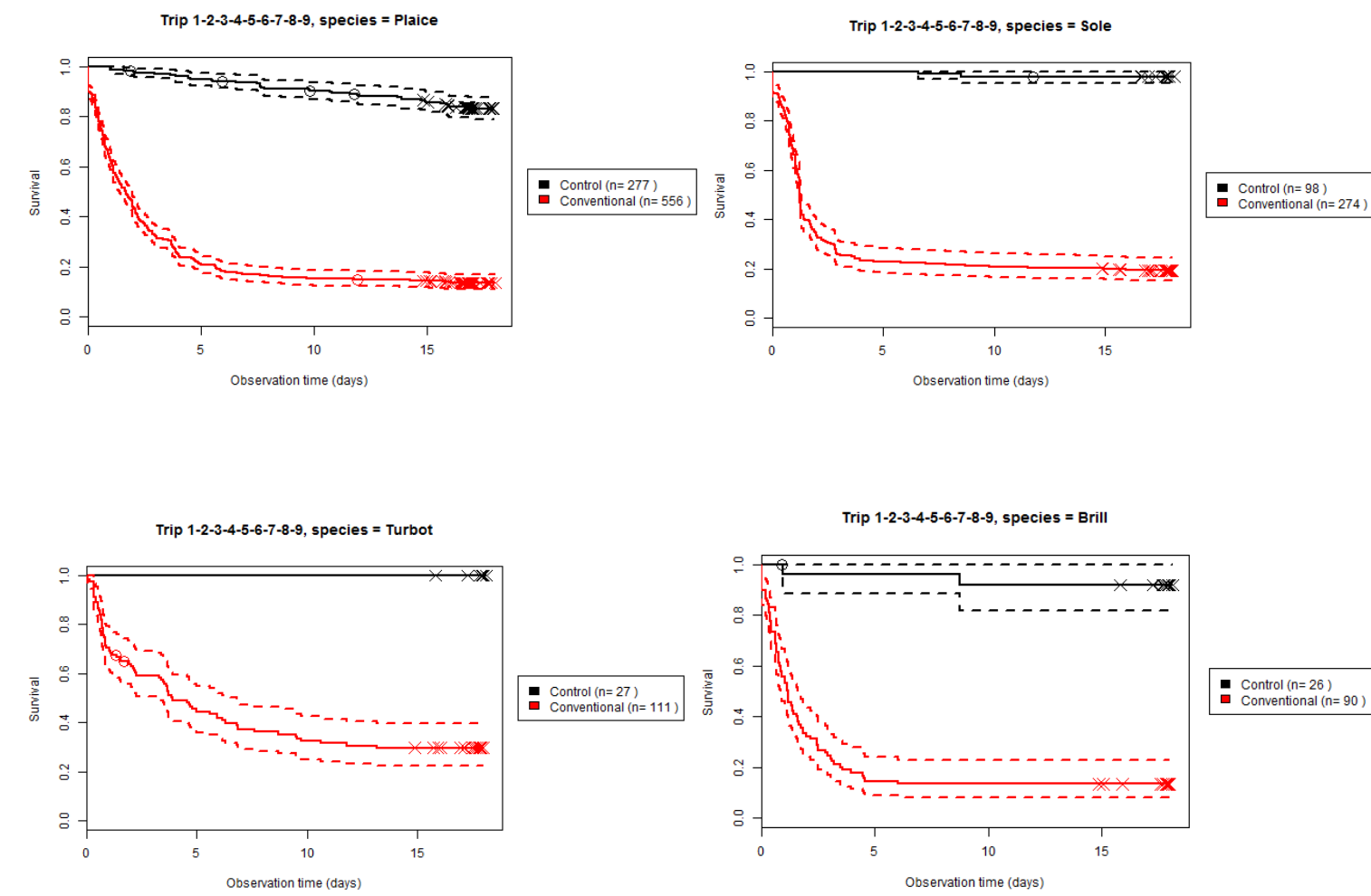

- Control $(n=26)$
Conventional $(n=90$

Trip 1-2-3-4-5-6-7-8-9, species $=$ Thornback ray
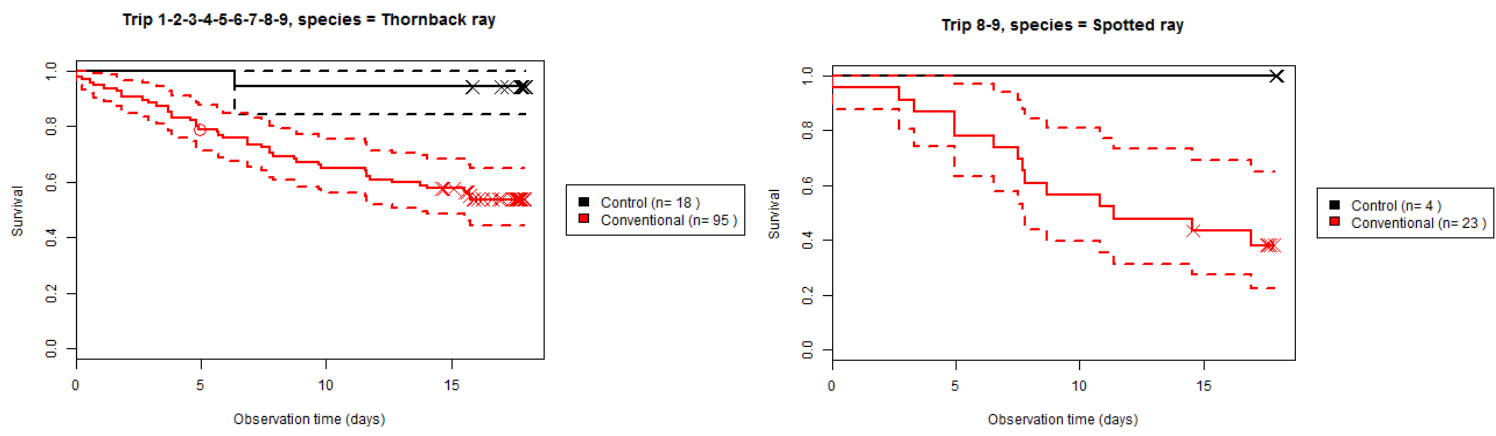

Figure 3. Kaplan Meier survival curves presenting survival (SD) for $n$ individuals over time for all trips combined for test (red) and control (black) fish. In the figures $X$ represent fish that is alive at the end of the experiment, $\mathrm{O}$ represent fish that died due to other causes than fishing mortality (e.g. technical failures) and were excluded from the experiment after $\mathrm{O}$.

\subsection{The effect of fish condition on discards survival}

Fish condition was assessed by giving a vitality index scores ( $A$ to $D$ ) to all individual test and controlfish (Table 3, page 13). Without exception all control-fish scored vitality index score $A$ and were thus in good condition as required for control-fish. Fish condition varied among test-fish. Absolute and relative counts as well as the estimates for discards survival probability per vitality index score over all sea trips combined are presented for all species in Table 7. Counts of vitality index scores per species for the individual sea trips are presented in Annex 2. Fish condition varied among sea trips in plaice $\left(X^{2} p=0.002\right)$, sole $\left(X^{2} p<0.0001\right)$, turbot (Fisher's exact test $\left.p=0.02\right)$ and thornback ray (Fisher's exact test $p=0.006$ ) but not in brill (Fisher's exact test $p=0.14$ ).

The majority ( $>60 \%$ ) of the test-fish collected for plaice, sole and brill was in poor condition (vitality index score $\mathrm{C}$ or $\mathrm{D}$, Table 3 ) while fish in the best condition, vitality index score $\mathrm{A}$, were observed in low numbers in plaice $(7 \%)$, brill $(8 \%)$ and sole $(10 \%)$. Most of the turbot were in good $(A, 42 \%)$ or 
relatively good $(B, 35 \%)$ condition (Table 7$)$. For thornback ray the distribution over fish in good to relatively good ( $A$ and $B$ ) and poor condition ( $C$ and $D$ ) was more or less balanced. For spotted ray the distribution over all vitality index scores was more or less balanced but it should be noted that the total number of sea trips (2) observations (22) is low for this species.

Table 7. Vitality index scores over all sea trips for all species (counts and relative frequencies) and the estimates for discards survival probability per vitality index class. Discards survival percentages with a different letter in superscript are different within species.

\begin{tabular}{|c|c|c|c|c|c|c|c|}
\hline \multirow[t]{2}{*}{ Species } & \multirow{2}{*}{$\begin{array}{c}\text { Vitality } \\
\text { index }\end{array}$} & \multirow[t]{2}{*}{ Count } & \multirow[t]{2}{*}{ Freq. } & \multicolumn{4}{|c|}{ Discards survival probability } \\
\hline & & & & Estimate & $\begin{array}{c}95 \% \mathrm{Cl} \\
\mathrm{LL}\end{array}$ & $\begin{array}{c}95 \% \mathrm{Cl} \\
\mathrm{UL}\end{array}$ & $\mathrm{p}$-value \\
\hline \multirow[t]{5}{*}{ Plaice } & A & 40 & $7 \%$ & $57 \%^{a}$ & $43 \%$ & $70 \%$ & \\
\hline & B & 158 & $29 \%$ & $27 \%^{\mathrm{b}}$ & $21 \%$ & $35 \%$ & \\
\hline & C & 167 & $30 \%$ & $4 \%^{c}$ & $2 \%$ & $9 \%$ & $<0.001$ \\
\hline & D & 188 & $34 \%$ & $3 \%^{c}$ & $2 \%$ & $7 \%$ & \\
\hline & All & 553 & $100 \%$ & & & & \\
\hline \multirow[t]{5}{*}{ Sole } & A & 27 & $10 \%$ & $74 \%^{a}$ & $54 \%$ & $88 \%$ & \\
\hline & B & 76 & $28 \%$ & $30 \%{ }^{\mathrm{b}}$ & $22 \%$ & $41 \%$ & \\
\hline & C & 93 & $34 \%$ & $9 \%^{c}$ & $5 \%$ & $15 \%$ & $<0.001$ \\
\hline & $\mathrm{D}$ & 78 & $28 \%$ & $3 \%^{c}$ & $1 \%$ & $7 \%$ & \\
\hline & All & 274 & $100 \%$ & & & & \\
\hline \multirow[t]{5}{*}{ Turbot } & A & 39 & $35 \%$ & $42 \%^{a}$ & $26 \%$ & $58 \%$ & \\
\hline & B & 46 & $42 \%$ & $31 \%^{a b}$ & $17 \%$ & $51 \%$ & \\
\hline & C & 20 & $18 \%$ & $8 \%^{b}$ & $2 \%$ & $31 \%$ & $<0.001$ \\
\hline & D & 6 & $5 \%$ & $0 \%^{c}$ & $0 \%$ & $0 \%$ & \\
\hline & All & 111 & $100 \%$ & & & & \\
\hline \multirow[t]{5}{*}{ Brill } & A & 7 & $8 \%$ & $44 \%^{a}$ & $17 \%$ & $74 \%$ & \\
\hline & B & 23 & $26 \%$ & $27 \%$ ab & $13 \%$ & $48 \%$ & \\
\hline & C & 21 & $23 \%$ & $8 \%{ }^{\mathrm{bc}}$ & $2 \%$ & $28 \%$ & 0.03 \\
\hline & D & 39 & $43 \%$ & $2 \%^{c}$ & $0 \%$ & $14 \%$ & \\
\hline & All & 90 & $100 \%$ & & & & \\
\hline \multirow[t]{5}{*}{ Thornback ray } & A & 12 & $13 \%$ & $84 \%^{a}$ & $47 \%$ & $97 \%$ & \\
\hline & B & 38 & $40 \%$ & $67 \%^{a}$ & $48 \%$ & $81 \%$ & \\
\hline & C & 33 & $34 \%$ & $42 \%^{b}$ & $24 \%$ & $63 \%$ & 0.01 \\
\hline & $\mathrm{D}$ & 12 & $13 \%$ & $9 \%^{c}$ & $1 \%$ & $49 \%$ & \\
\hline & All & 95 & $100 \%$ & & & & \\
\hline \multirow[t]{5}{*}{ Spotted ray } & A & 5 & $23 \%$ & $70 \%$ & $28 \%$ & $93 \%$ & \\
\hline & B & 8 & $36 \%$ & $50 \%$ & $12 \%$ & $88 \%$ & \\
\hline & C & 5 & $23 \%$ & $20 \%$ & $2 \%$ & $79 \%$ & 0.59 \\
\hline & $\mathrm{D}$ & 4 & 185 & $30 \%$ & $8 \%$ & $70 \%$ & \\
\hline & All & 22 & $100 \%$ & & & & \\
\hline
\end{tabular}

Survival curves per vitality index score are presented per species in Figure 4. Fish condition has a strong effect on discards survival (Figure 4,Table 7). Significant differences among discards survival per vitality index score were detected in all species except spotted ray (Table 7). Without exception the highest and lowest discards survivals were observed for vitality index scores A and D. Clearly survival declines with deteriorating fish condition (Table 7).

For plaice, survival varied from $57 \%$ for class A to very low survival for class C (4\%) and class D ( $3 \%$ ). For sole a similar pattern was observed, with even higher survival ( $74 \%$ ) for fish in good condition (A). For both species approximately $40 \%$ of the test-fish that scored a vitality score $D$ was dead at the time of vitality index scoring. Turbot in poor condition (D) all die within one day after collection, while survival is $42 \%$ among turbot in good condition (A). For brill survival varied from $44 \%$ for fish in good condition (A) to $2 \%$ for fish in poor condition (D). Thornback ray in good condition (A) 
showed survival as high as $84 \%$. In contrast, fish in poor condition (D) all except one died within five days after collection.

\subsection{The effect of catch-processing time on discards survival probability and fish condition}

The effect of catch-processing time (maximum 34 minutes, Table 1, page 7), the time difference between discharging the catch in the hoppers and collection from the sorting belt, on discards survival probability was explored. No effect of catch-processing time on discards survival probability could be detected in any species tested (binary mixed modelling, $p=0.21$ for sole, $p=0.85$ for turbot, $p=$ 0.97 for brill, $p=0.53$ for thornback ray and $p=0.38$ for spotted ray).

For plaice the catch-processing time was affected by the separate and alternated processing of the hoppers. The hopper from which the plaice were collected was either processed before or after the other hopper was processed, with three hauls per sea trip for both scenarios (see 2.1.4). In case the hopper from which the plaice were sampled was processed after the other hopper, the plaice were left waiting for approximately 15 minutes until processing of the catch in the other hopper had been completed. As for this distinct difference in catch-processing, the effect of catch-sorting time on plaice discards survival was considered separately for the plaice that were collected from the immediately processed catches (first-processed) and the catches that were left waiting (last-processed). For both groups, no effect of catch-processing time on discards survival probability could be detected (binary mixed modelling, $p=0.48$ (first processed) and 0.09 (last-processed)).

The separate processing of the hoppers when plaice were collected, offered the opportunity to explore the effect on discards survival of leaving the catch to wait for circa 15 minutes in the hopper before processing or process the catches immediately. No effect of this 15 minutes 'air exposure' were detected for plaice discards (multilevel logistic regression, $p=0.90$ ). Survival probability estimates were $14 \%(95 \% \mathrm{Cl} 10-20 \%)$ for plaice from catches that were processed immediately and $14 \%$ $(95 \% \mathrm{Cl} 10-19 \%)$ for the plaice from catches that were left to wait for 15 minutes in the (dry) hopper before catch-processing started. Since the 15 minutes 'air exposure' did not affect survival probability, the effect of catch-processing time on plaice discards survival probability could be tested for all plaice test-fish combined. Survival probability estimates for plaice that were collected at the start (18\%, $95 \% \mathrm{Cl} 14-23 \%)$ and the end of the catch sorting process (13\%, 95\% Cl $9-19 \%$ ) were not significantly different (multilevel logistic regression, $p=0.15$ ).

To assess if catch-processing time affects fish condition, mean values for catch-sorting time differences per vitality index class were tested for differences (Table 8). Catch-processing time differed among vitality index score classes A, B, C and D for plaice, turbot and brill. No such effect was detected in sole, thornback and spotted ray.

Table 8. Mean catch-processing time per vitality index score. Within species, mean values with the same letter superscript are significantly different (REML, $p<0.05$ ).

\begin{tabular}{|c|c|c|c|c|c|c|}
\hline \multirow{2}{*}{ Vitality index } & \multicolumn{6}{|c|}{ Mean catch-processing time (min) } \\
& Plaice & Sole & Turbot & Brill & Thornback ray & \multicolumn{1}{c|}{ Spotted ray } \\
\hline A & $13.0^{\mathrm{ab}}$ & 8.5 & $7.1^{\mathrm{ac}}$ & $6.9^{\mathrm{a}}$ & 8.2 & 5.0 \\
\hline B & $12.2^{\mathrm{a}}$ & 10.1 & $10.0^{\mathrm{b}}$ & $10.3^{\mathrm{b}}$ & 9.8 & 9.6 \\
\hline C & $13.5^{\mathrm{b}}$ & 10.0 & $11.4^{\mathrm{b}}$ & $10.0^{\mathrm{b}}$ & 8.4 & 6.1 \\
\hline D & $13.3^{\mathrm{b}}$ & 8.8 & $10.4^{\mathrm{bc}}$ & $8.3^{\mathrm{ab}}$ & 9.6 & 14.6 \\
\hline p-value & 0.004 & 0.19 & 0.002 & 0.04 & 0.22 & 0.10 \\
\hline
\end{tabular}


Figure 4. Discards survival over all trips per vitality index class per species. In the figures $\mathrm{X}$ represents fish that is alive at the end of the experiment, $O$ represents fish that died due to other causes than fishing mortality (e.g. technical failures) and were excluded from the experiment after time $\mathrm{O}$.
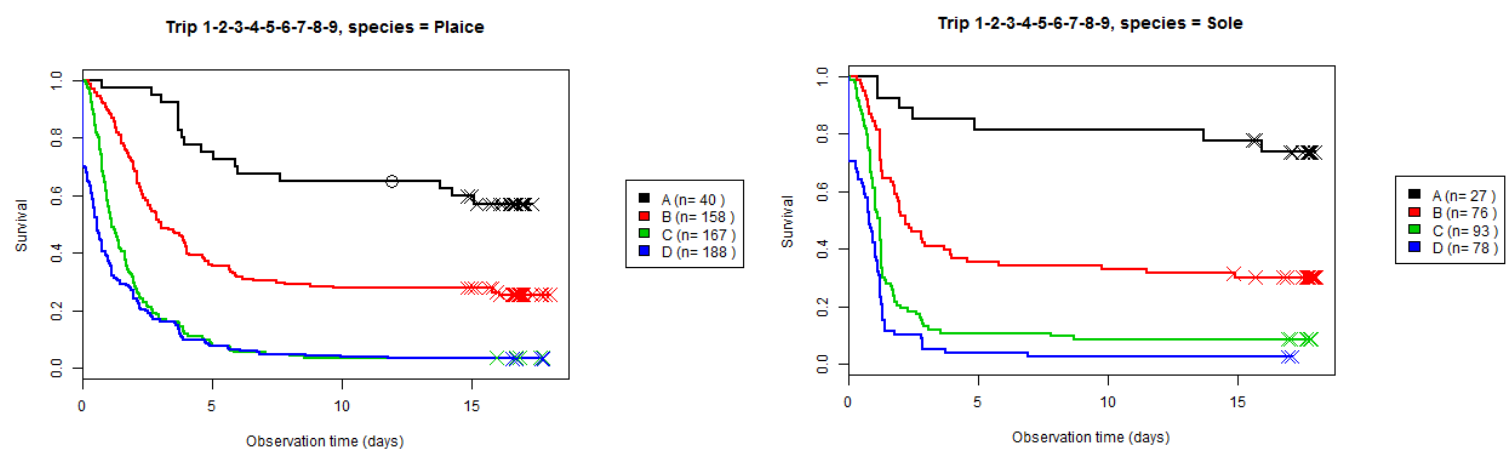

Trip 1-2-3-4-5-6-7-8-9, species $=$ Turbot
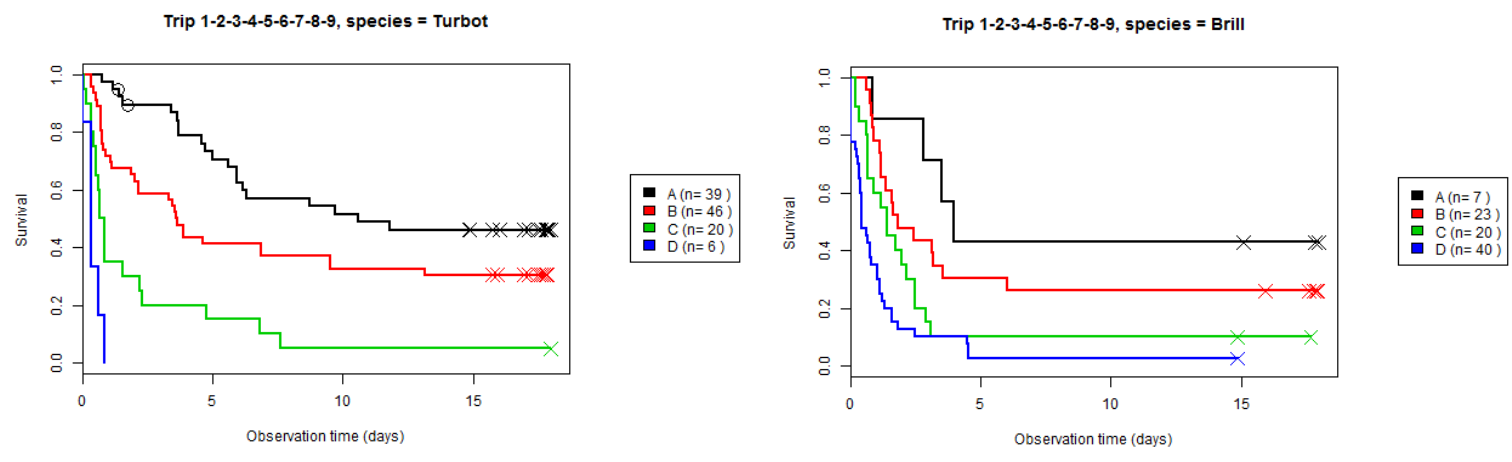

Trip 1-2-3-4-5-6-7-8-9, species $=$ Thornback ray
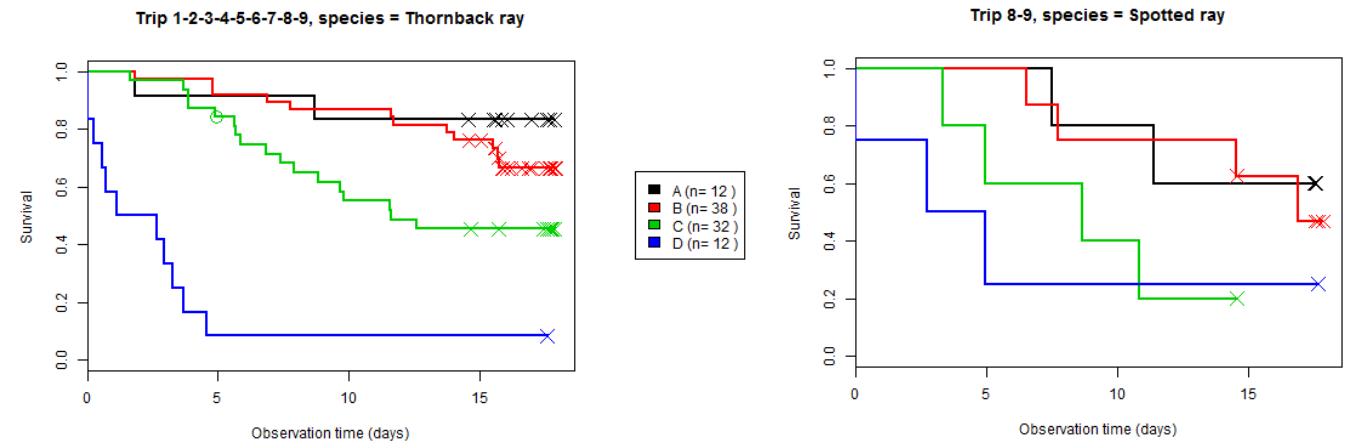


\section{Discussion}

\subsection{Discards survival}

The current study estimated discards survival probabilities for undersized plaice, sole, turbot, brill, thornback ray and spotted ray in the $80 \mathrm{~mm}$ pulse-trawl fisheries.

Control-fish were deployed to detect any mortality potentially caused by the experimental procedures instead of being fisheries induced. Survival among control fish over all nine sea trips was consistently high at $84 \%$ for plaice and $>90 \%$ for all other species tested. The lower survival among plaice control fish is caused by three trips with lower than $90 \%$ survival. We attribute the low control fish survival of $30 \%$ in sea trip 5 to the poor state the control plaice were in prior to the sea trip rather than the experimental procedures, even though this not reflected by the vitality index scores of these fish. We cannot explain the lower survival (72\%) among plaice control fish in sea trips 7 and 8 . However, since the mortality among control fish started after the mortality in the test-fish had already stabilized, we do not attribute this mortality to the experimental procedures at sea. Jointly taken, we cannot entirely exclude that the experimental procedures caused some additional mortality on top of the fisheries induced mortality, especially among test-fish for plaice but also the other species. Since survival probability estimates were not correct in case control-fish survival was $<100 \%$, the presented survival probability estimates may be slight underestimations. On the other hand, it cannot be excluded that the presented survival probabilities are slight overestimations because potential postdiscarding predation by sea birds and other species was not incorporated in the experiment, although it is unknown to what extent the discarded fish are preyed upon when discarded.

The variation in the observed discards survival was high among the sea trips performed throughout the year. Discards survival probability estimates differed among sea trips in all species except brill. Considering the overall low survival of brill and the subsequent narrow survival range among sea trips, we suspect that the number of observations was too low to detect an effect of sea trips on survival probability of brill rather than that the effect is entirely absent. In line with the finding of Van der Reijden et al. (2017) that water temperature affects discards survival, we consider the variation in discards survival among sea trips we observed in the current study a reflection of variation in environmental and physical conditions among fishing trips rather than experimental variation. It seems clear that year-round assessment under various fishing conditions is required to obtain survival probability estimates that are representative for year-round fisheries. Our further studies, using the data collected in the current experiment, aim to establish relations between factors such as temperature, catch composition and sea state and discards survival probability.

The overall discards survival probability for plaice was estimated at $14 \%$ with a $95 \%$ confidence interval of 11 to $18 \%$. Our estimate agrees well with the previous reported survival probability of plaice discards in pulse-trawl fisheries of $15 \%$ with a $95 \%$ confidence interval of 11 to $19 \%$ (Van der Reijden et al., 2017). Given the agreement between these two studies of highly comparable set-up and the large number of observations (558) we collected year-round, it is reasonable to consider the survival probability of $14 \%(95 \% \mathrm{Cl} 11-18 \%)$ to be a good estimate of the actual overall survival probability of plaice discards $(<27 \mathrm{~cm})$ in the $80 \mathrm{~mm}$ pulse-trawl fisheries.

The overall discards survival probability for sole was estimated a $19 \%$ with a $95 \%$ confidence interval of 13 to $28 \%$. Survival probability of sole discards estimated in the current study seems lower than the previously reported $29 \%(95 \% \mathrm{Cl} 24-35 \%)$ survival probability of sole discards in pulse-trawl fisheries (Van der Reijden et al., 2017), although the 95\% confidence intervals show some overlap. The lower survival probability of sole discards estimated in the current study can probably be attributed to the very low survival observed in the sea trips in the winter months December, January and February, while observations in those months were absent in the study by Van der Reijden et al. (2017). In addition, we did not assess sole discards survival in March and April while Van der Reijden et al. (2017) reports relatively high survival of $37.5 \%$ and $36.4 \%$ for their trips in April. This probably means that the actual overall and year-round sole discards survival probability lies between 19 and 
$29 \%$. A more precise estimate for the sole discards survival probability could be obtained by merging the data of both studies, but this lies beyond the scope of the current study.

Future insights in how various fishing conditions affect discards survival, may result in further refining of our current estimates of discards survival probability for plaice and sole, especially when determining factors can be taken into account according to the frequency of their occurrence.

This study provides the first estimates for the survival probability of turbot and brill discards in pulsetrawl fisheries. Also in other types of fisheries, survival of discards has not been studied for these species. The survival of turbot discards ranged from $0 \%$ to $63 \%$ among sea trips. The overall discards survival probability for turbot was estimated at $30 \%$ with a $95 \%$ confidence interval of 20 to $43 \%$. In brill the survival was lower with a range from $0 \%$ to $33 \%$ among sea trips and overall survival probability estimate of $13 \%$ with a $95 \%$ confidence interval of 7 to $23 \%$. Since all turbot and brill were collected during the same sea trips and in most cases even from the same hauls, it is reasonable to consider 'species' the dominant factor that explains the seemingly distinct difference in discards survival between the two species. Although no direct comparison of fish condition was made between species, it seems that turbot collected from the catches not only displayed higher survival but also were in better condition than brill. Maybe the spikes in the skin of the turbot, which are absent in brill, is one of the traits that make turbot more robust to the physical impacts of the capture and sorting process than brill. Brill on the other hand appeared to be susceptible to scale loss and subsequent infection of the affected areas, although it is not clear whether this caused mortality.

Also for thornback ray and spotted ray this study provides the first estimates for discards survival probabilities in pulse-trawl fisheries. The survival of thornback ray discards ranged from 0 to $82 \%$ among sea trips. The overall discards survival probability for thornback ray was estimated at $53 \%$ with a $95 \%$ confidence interval of 40 to $65 \%$. Spotted ray discards were collected during two sea trips only which resulted in discards survivals of 21 and $67 \%$. Spotted ray was included in the program to gain insight in the variation in discards survival among the different ray species that are caught by pulsetrawling in the North Sea. In a discards survival study in commercial twin-rig otter trawl fisheries it was found that among the various ray species tested, thornback ray and spotted ray had similar shortterm survival of $59 \%$ and $55 \%$ (Enever et al., 2009). The physical protection offered by the more accentuated spinulose of thornback ray was suggested to explain the (slightly) higher survival compared to other ray species. In line with this notion, we expected discards survival in spotted ray to be lower than in thornback ray. However, thornback and spotted rays that were collected during the same sea trips and in most cases even from the same hauls, resulted in a seemingly higher survival among spotted rays compared to thornback rays. The limited observations in our experiment do not allow for statistical comparison of the survival observed for both ray species, but two trips in which both species were collected do not suggest a large difference in discards survival between the two species.

Discards survival of various ray species has been assessed in demersal fisheries in British waters. Short-term survival ( $72 \mathrm{~h}$ ) of $55 \%$ was reported for thornback ray discards in twin rig otter trawls (Enever et al., 2009). In the pulse trawl fishery thornback ray survival was $>85 \%$ at $72 \mathrm{~h}$ monitoring. Long-term survival was probably lower than the reported short-term survival given our observations that it takes 5 to 10 days for post-capture mortality of rays to stabilize. Nevertheless, ray discards survival in demersal fisheries appears to be relatively high compared to the survival of discards of flat fish species.

The discards survival probability estimates reported here for turbot, brill and thornback ray are based on limited numbers of observations per species. These estimates should therefore be considered and treated as a first indication of the actual discards survival probability for these species in the $80 \mathrm{~mm}$ pulse-trawl fisheries. Although we expect discards survival to vary among observations throughout the year, collection of more data will probably narrow down the current $95 \%$ confidence intervals and give more precise estimates for the survival probability. We expect that these more precise estimates will lie within the current $95 \%$ confidence intervals for the survival probability estimates. Discards survival probabilities for these species then at least equal the lower limits of the current $95 \%$ confidence intervals. 


\subsection{Effect of fish condition on discards survival}

Clearly fish condition varied among the test-fish we collected at sea. Test-fish grouped by vitality index scores shown clear differences in survival at the end of the monitoring period in all species tested. Even in turbot, brill and thornback ray for which the number of observations is relatively small, significant differences in survival probability among vitality index scores were detected. Only in spotted rays the number of observations was too small to detect this effect. In thornback ray the difference in survival probability estimates between fish categorized A and D was as large as $75 \%$. This difference between fish categorized $A$ and $D$ was also pronounced in sole $(71 \%)$, plaice $(54 \%)$, turbot (42\%) and brill (42\%). Without exception vitality index scores A and D always yields the highest and lowest discards survival among the species tested. It is clear that the condition in which the fish arrive on the sorting belt has a strong effect on their survival chances when discarded.

While the survival of discarded fish in good condition may be high, their contribution to the overall discards survival is small as the proportion of fish in good condition in the catches is often low (Table 7, page 17). In fact, most fish in the catches are in poor condition, which reduces overall discards survival. Turbot appears to be an exception with most test-fish in the catches in good condition. Indeed the discards survival observed for turbot is among the highest in this experiment. It is clear that measures that aim to increase discards survival should focus on improving the condition of discarded fish.

Fish condition varied among sea trips. In our further studies we will explore to what extent this variation in fish condition can be explained by the various conditions under which the sea trips took place. This may result in novel insights on how to improve the condition of fish in catches, provided variation in fish condition among sea trips was at least to some extent determined by factors that can be manipulated.

\subsection{Effect of catch-processing time on discards survival probability and fish condition}

Prior to processing, catches in the hoppers may be exposed to air for up to 15 minutes when the crew first shoots the trawls after emptying the cod-ends. The catch-sorting process took up to 35 minutes depending on catch size and composition, the nature of the catch-sorting process on individual vessels and the time needed to shoot the trawls prior to catch-processing. When processing the catch from the hoppers, fish are transported by a conveyer belt onto a sorting belt (Figure 2). Marketable fish are manually taken from the sorting belt by the vessel's crew. The rest of the catch, including discards, drops off the end of the sorting-belt into a gutter which discharges into the sea. In this process fish are exposed to air and physical impacts with other fish, heavy water jets, benthic fauna, abiotic debris, the hopper, and the belts, which all potentially affect discards survival chances. Catchprocessing time, duration of the air and impact exposure, has been suggested to affect discards survival (Benoit et al., 2013, Van der Reijden et al., 2017). We therefore collected test-fish both at the start and the end of the catch sorting process to obtain representative samples from catches. Given the earlier findings by Benoit et al. (2013) and Van der Reijden et al. (2017) and since a longer catchsorting process results in longer exposure to air and potentially more physical impacts, we predicted discards survival to decrease with increasing catch-processing time. Surprisingly, no effect of catchprocessing time on survival probability could be detected in any of the species tested. A plausible, but yet to be established, explanation for the absence of such effect is that impact of the catching-sorting process, if any, is overruled by the impact of the capture process.

The separate processing of the hoppers when plaice were collected, offered the opportunity to explore the effect on discards survival of leaving the catch to wait for circa 15 minutes in the hopper before processing versus catch-processing immediately after shooting the trawls. While in the hopper, the fish are out of the water and susceptible to e.g. oxygen shortage and dehydration. Surprisingly, survival probability of plaice that were left to wait for 15 minutes before processing, showed no decrease compared the plaice that were processed immediately. Apparently, this 'air exposure' up to 
15 minutes, or even up to 30 minutes when the time to shoot the trawls before catch-processing is started is taken into account, has no negative effect on survival chances of plaice discards.

Given the strong effect of fish condition on survival chances of discards, we predicted that an effect of catch-sorting time on discards survival would be at least partly caused by deterioration of fish condition as the catch-sorting process progresses. To investigate the effect of the duration of the catch-sorting process on fish condition we compared mean catch-processing times among test-fish grouped by their vitality index scores. Although no effect of catch processing time on discards survival probability was detected, significant differences in catch-sorting times appeared among plaice, turbot and brill test-fish grouped by vitality index scores. These observations however do not seem to indicate deterioration of fish condition during the catch-sorting process as catch-processing times of fish in the best vitality index score (A) and the worst vitality index score (D), are the same within all three species. In addition, the absolute differences between catch-processing time per vitality index group are too small to provide any practical leads to improve fish condition by a faster catch-sorting process. 


\section{Conclusions and recommendations}

Discards survival probability estimates and their 95\% confidence intervals were established for undersized plaice, sole, turbot, brill and thornback ray in the $80 \mathrm{~mm}$ pulse-trawl fisheries.

The discards survival probability for undersized plaice was estimated at $14 \%(95 \% \mathrm{Cl} 11-18 \%)$. This result can be considered representative for the overall survival probability for undersized plaice in the $80 \mathrm{~mm}$ pulse-trawl fisheries.

The discards survival probability for undersized sole was estimated at $19 \%(95 \% \mathrm{Cl} 13-28 \%)$. Although this estimate was based on observations obtained year-round, it cannot be excluded that the overall survival probability for undersized sole is slightly higher. We therefore recommend to merge the data collected in the current study with the data previously collected by Van der Reijden et al. (2017). Such data merge is appropriate because both studies used very similar methods to measure discards survival. We expect that the observations in the combined data set provide improved coverage of the varying conditions throughout the year and therefore a more precise estimate of the discards survival probability for undersized sole in the $80 \mathrm{~mm}$ pulse-trawl fisheries.

The discards survival probabilities for by-catch species were estimated at $30 \%(95 \% \mathrm{Cl} 20-43 \%)$ for turbot, $13 \%(95 \% \mathrm{Cl} 7-23 \%)$ for brill and 53\% (95\% Cl 40-65\%) for thornback ray. As for the limited number of observations on which these estimates are based, they should be considered and treated as first indications of the actual discards survival probabilities for these species in the $80 \mathrm{~mm}$ pulse-trawl fisheries. The lower limits of the $95 \%$ confidence intervals may be used as conservative discards survival probability estimates. In case more precise estimates are required for these species, we recommend to collect more data using the methods used in the current study.

All these discards survival probability estimates apply to year-round pulse-trawl fisheries. In all species, discards survival shows variation throughout the year. This means that the presented overall survival probability for a species is not necessarily representative for its discards survival in any specific time of the year. The nature of this variation remains to be established..

In all species tested, discards survival was strongly affected by fish condition. We therefore recommend that measures aimed at increasing discards survival focus on improving the condition of discarded fish. Since catch-processing time seems to have no effect on fish condition nor discards survival, we recommend that measures aimed at improving the condition of discarded fish focus on the fish capture process rather than catch processing.

In addition to the above, data on the effects of environmental factors on discards survival as well as on predicting discards survival probabilities using vitality index, reflex impairment and damage scoring were also collected in the current study. The results of these additional investigations will be presented in following reports. 


\section{Acknowledgements}

This study was commissioned by VISNED, The Netherlands. This study was partly funded by the European Union, European Maritime and Fisheries Fund (EMFF). The authors would like the following persons and organisations for their indispensable contributions to this project. The owners, skippers and crews of the UK33, TX3 and GO23 for welcoming researchers on board of their vessels and enabling research at sea. The skippers and crews of the TH10 and OD3 for collecting control-fish at sea. Richard Martens and Wouter van Broekhoven for project management. Pim van Dalen, Ainhoa Blanco, Ad van Gool, Emiel Brummelhuis and Yoeri van Es for all the practical work related to the collection of control-fish, preparation of sea trips and survival monitoring in the laboratory. Van Wijk installaties en constructies BV, Maaskant Shipyards Stellendam BV and Visserij Coöperatie Urk (VCU) for preparing and installing the technical installations at the vessels required for the research. Ewout Blom, Nathalie Steins, J oe Freijser (De Aquanoom), Raoul Kleppe (Wageningen University) and Pim Boute (Wageningen University) for taking part in the sea trips. Mulder Transport BV for transporting the survival monitoring units between vessels and the laboratory. Schreuder Transport BV and Steketee BV for transporting equipment and control-fish to the vessels. Tom Catchpole (CEFAS) for guidance with the protocols for reflex scoring in rays. Sebastian Uhlmann (ILVO) for providing training in reflex scoring in turbot and brill. Jan Jaap Poos, Sander Glorius and Pepijn de Vries for their assistance in data analysis. 


\section{$7 \quad$ Quality Assurance}

Wageningen Marine Research utilises an ISO 9001:2008 certified quality management system (certificate number: 187378-2015-AQ-NLD-RvA). This certificate is valid until 15 September 2018. The organisation has been certified since 27 February 2001. The certification was issued by DNV Certification B.V.

Furthermore, the chemical laboratory at IJ muiden has NEN-EN-ISO/IEC 17025:2005 accreditation for test laboratories with number L097. This accreditation is valid until $1^{\text {th }}$ of April 2021 and was first issued on 27 March 1997. Accreditation was granted by the Council for Accreditation. The chemical laboratory at IJ muiden has thus demonstrated its ability to provide valid results according a technically competent manner and to work according to the ISO 17025 standard. The scope (L097) of de accredited analytical methods can be found at the website of the Council for Accreditation (www.rva.nl).

On the basis of this accreditation, the quality characteristic $Q$ is awarded to the results of those components which are incorporated in the scope, provided they comply with all quality requirements. The quality characteristic $Q$ is stated in the tables with the results. If, the quality characteristic $Q$ is not mentioned, the reason why is explained.

The quality of the test methods is ensured in various ways. The accuracy of the analysis is regularly assessed by participation in inter-laboratory performance studies including those organized by QUASIMEME. If no inter-laboratory study is available, a second-level control is performed. In addition, a first-level control is performed for each series of measurements.

In addition to the line controls the following general quality controls are carried out:

- Blank research.

- Recovery.

- Internal standard

- Injection standard.

- Sensitivity.

The above controls are described in Wageningen Marine Research working instruction ISW 2.10.2.105. If desired, information regarding the performance characteristics of the analytical methods is available at the chemical laboratory at IJ muiden.

If the quality cannot be guaranteed, appropriate measures are taken. 


\section{References}

Benoît, H.P., Plante, S., Kroiz, M., Hurlbut, T. 2013. A comparative analysis of marine fish species susceptibilities to discard mortality: effects of environmental factors, individual traits, and phylogeny. ICES J ournal of Marine Science $70(1,1), 99-113$.

Enever, R., Catchpole, T.L., Ellis, J.R., Grant, A. 2009. The survival of skates (Rajidae) caught by demersal trawlers fishing in UK waters. Fisheries Research 97 (1-2).

European Union. 2013. REGULATION (EU) No 1380/2013 OF THE EUROPEAN PARLI AMENT AND OF THE COUNCIL of 11 December 2013 on the Common Fisheries Policy, amending Council Regulations (EC) No 1954/2003 and (EC) No 1224/2009 and repealing Council Regulations (EC) No 2371/2002 and (EC) No 639/2004 and Council Decision 2004/585/EC. Official Journal of the European Union, L354/22

ICES. 2016. Report of the Workshop on Methods for Estimating Discard Survival 4 (WKMEDS4), 30 November-4 December 2015, Ghent, Belgium. ICES CM 2015\ACOM: 39. 57 pp.

Kaplan, E.L., Meier, P. 2012. Nonparametric Estimation from Incomplete Observations, Journal of the American Statistical Association, 53:282, 457-481,

Van der Reijden, K. J., Molenaar, P., Chen, C., Uhlmann, S.S., Goudswaard, P.C. Van Marlen, B. 2017. Survival of undersized plaice (Pleuronectes platessa), sole (Solea solea), and dab (Limanda limanda) in North Sea pulse-trawl fisheries. ICES J ournal of Marine Science 74(6), 1672-1680. 


\section{Justification}

Report number:

$\mathrm{C} 037 / 18$

Project number:

4311400003

The scientific quality of this report has been peer reviewed by a colleague scientist and a member of the Management Team of Wageningen Marine Research.

Programme manager

Signature:

Date:

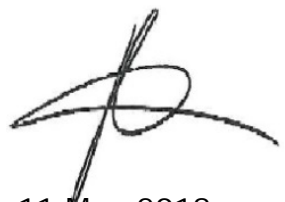

11 May 2018

Approved:

Dr. ir. T.P. Bult

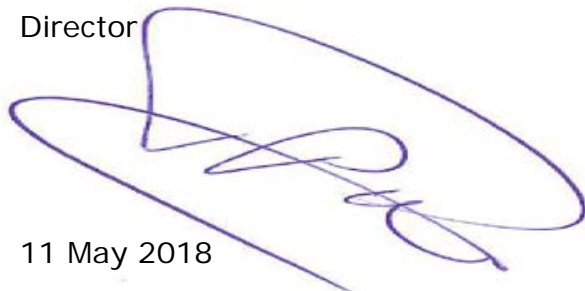

Date:

11 May 2018 


\section{Annex 1: Survival per trip}

\section{Trip 1}

\begin{tabular}{|c|c|c|c|c|c|c|c|c|c|c|c|}
\hline Trip & Vessel & Year & Month & Week & $\begin{array}{c}\text { Air } \\
\text { temperatur } \\
\mathrm{e}\left({ }^{\circ} \mathrm{C}\right)\end{array}$ & $\begin{array}{c}\text { Water } \\
\text { temperatur } \\
\mathrm{e}\left({ }^{\circ} \mathrm{C}\right)\end{array}$ & $\begin{array}{c}\text { Wind speed } \\
(\mathrm{Bft})\end{array}$ & $\begin{array}{c}\text { Wave } \\
\text { height }(\mathrm{m})\end{array}$ & $\begin{array}{c}\text { Catch } \\
\text { processing } \\
(\mathrm{min})\end{array}$ & $\begin{array}{c}\text { Haul } \\
\text { duration } \\
(\mathrm{min})\end{array}$ & $\begin{array}{c}\text { Fishing } \\
\text { depth }(\mathrm{m})\end{array}$ \\
\hline 1 & UK33 & 2017 & May & 18 & - & $9-12$ & $2-5$ & $0.5-2.0$ & 30 & $110-135$ & $18-28$ \\
\hline
\end{tabular}

\begin{tabular}{|c|c|c|c|c|c|c|c|c|c|c|c|}
\hline \multicolumn{2}{|c|}{ Plaice } & \multicolumn{2}{c|}{ Sole } & \multicolumn{2}{c|}{ Turbot } & \multicolumn{3}{c|}{ Brill } & \multicolumn{2}{c|}{ Spotted ray } \\
\hline \# Test & \#Control & \# Test & \#Control & \# Test & \#Control & \# Test & \#Control & \# Test & \#Control & \# Test & \#Control \\
\hline $\mathbf{1 5 \%}$ & $100 \%$ & $\mathbf{4 5 \%}$ & $100 \%$ & $\mathbf{4 4 \%}$ & $100 \%$ & $\mathbf{3 3} \%$ & $100 \%$ & $\mathbf{4 0 \%}$ & $100 \%$ & - & - \\
\hline
\end{tabular}

Trip 1 - species Plaice

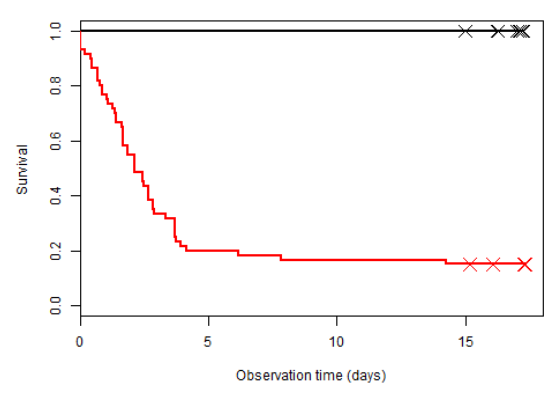

Trip 1 - species Turbot

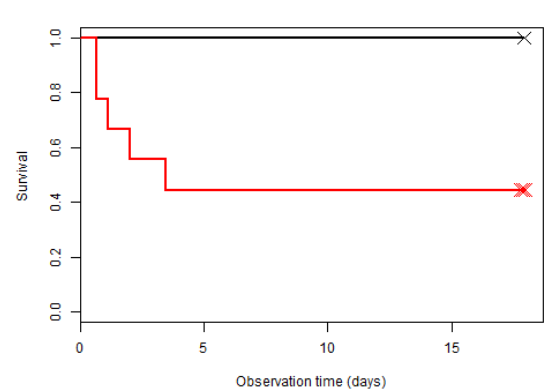

Trip 1 - species Thornback ray

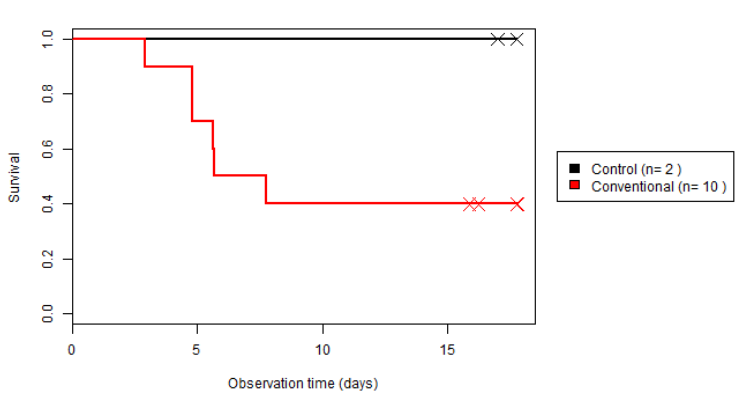

Trip 1 - species Sole

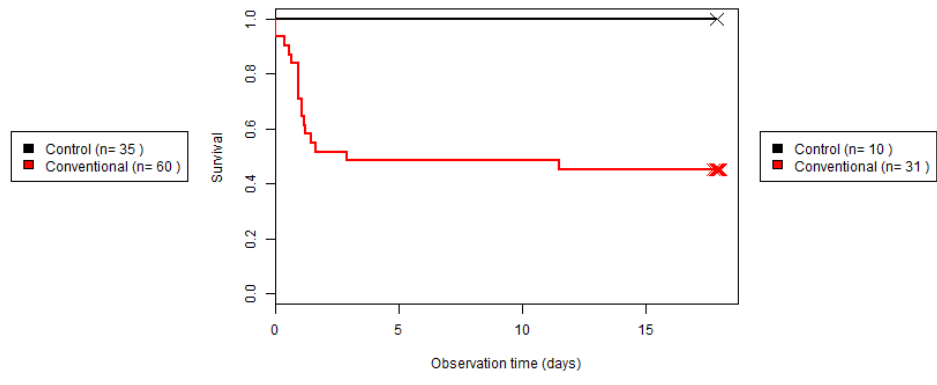

Trip 1 - species Brill

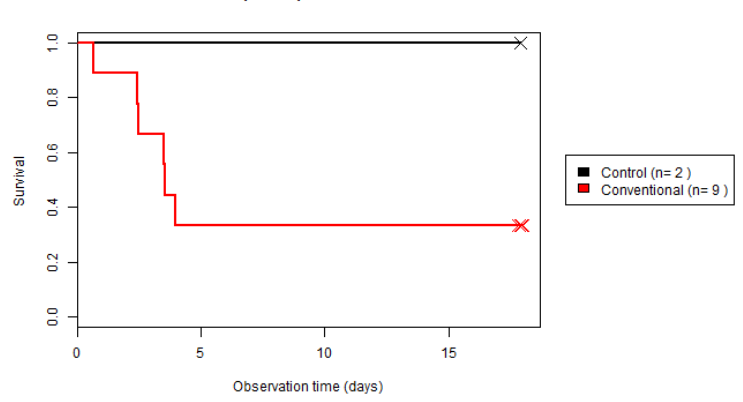




\section{Trip 2}

\begin{tabular}{|c|c|c|c|c|c|c|c|c|c|c|}
\hline Trip & Vessel & Year & Month & Week & $\begin{array}{c}\text { Air } \\
\text { temperatur } \\
\mathrm{e}\left({ }^{\circ} \mathrm{C}\right)\end{array}$ & $\begin{array}{c}\text { Water } \\
\text { temperatur } \\
\mathrm{e}\left({ }^{\circ} \mathrm{C}\right)\end{array}$ & $\begin{array}{c}\text { Wind speed } \\
\text { (Bft) }\end{array}$ & $\begin{array}{c}\text { Wave } \\
\text { height }(\mathrm{m})\end{array}$ & $\begin{array}{c}\text { Catch } \\
\text { processing } \\
(\mathrm{min})\end{array}$ & $\begin{array}{c}\text { Haul } \\
\text { durationth }(\mathrm{m}) \\
(\mathrm{min})\end{array}$ \\
\hline 2 & $\mathrm{GO} 23$ & 2017 & May & 21 & $14-19$ & $12-13$ & $0-4$ & $0.2-0.5$ & 24 & 120 \\
\hline
\end{tabular}

\begin{tabular}{|c|c|c|c|c|c|c|c|c|c|c|c|}
\hline \multicolumn{2}{|c|}{ Plaice } & \multicolumn{2}{|c|}{ Sole } & \multicolumn{2}{|c|}{ Turbot } & \multicolumn{2}{|c|}{ Brill } & \multicolumn{2}{|c|}{ Thornback ray } & \multicolumn{2}{|c|}{ Spotted ray } \\
\hline \# Test & \#Control & \# Test & \#Control & \# Test & \#Control & \# Test & \#Control & \# Test & \#Control & \# Test & \#Control \\
\hline $15 \%$ & $97 \%$ & $50 \%$ & $100 \%$ & $55 \%$ & $100 \%$ & $25 \%$ & $100 \%$ & $82 \%$ & $100 \%$ & - & - \\
\hline
\end{tabular}

Trip 2 - species Plaice

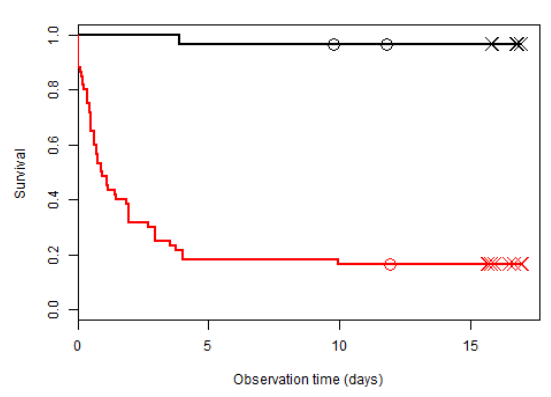

Trip 2 - species Turbot

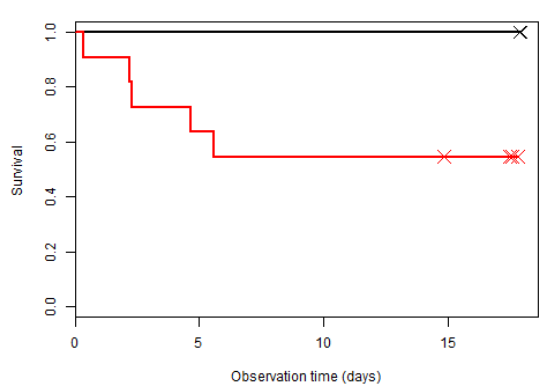

Trip 2 - species Thornback ray

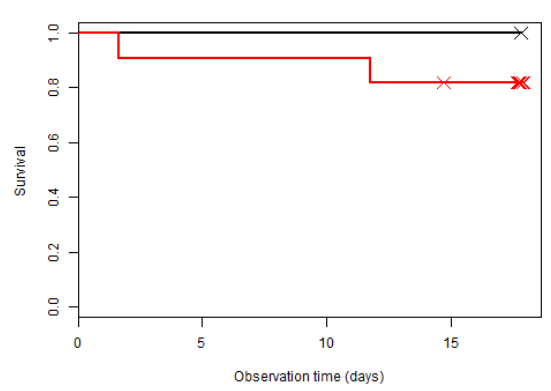

Trip 2 - species Sole

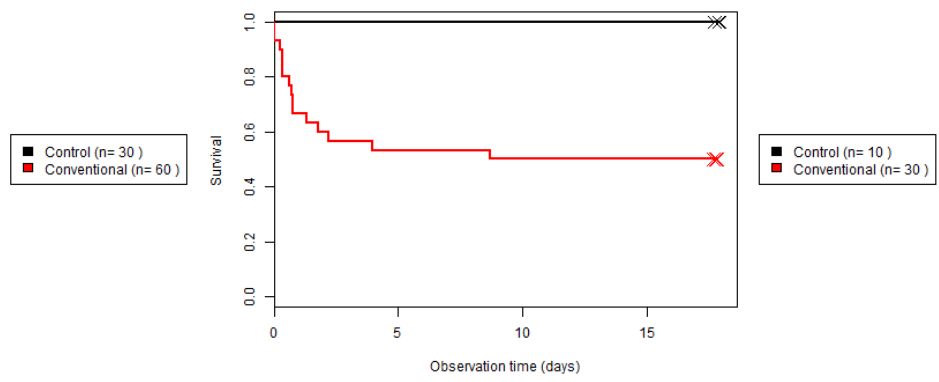

Trip 2 - species Brill

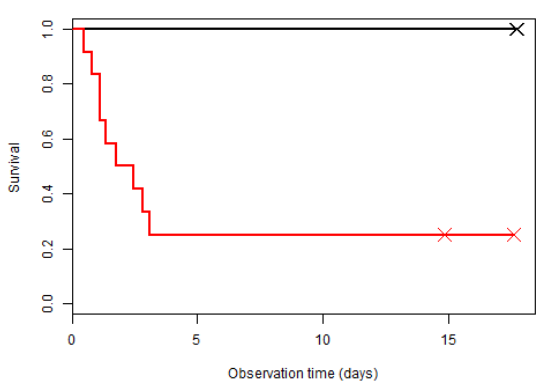

- Control $(n=3)$

- Control $(n=3)$
Conventional $(n=11)$

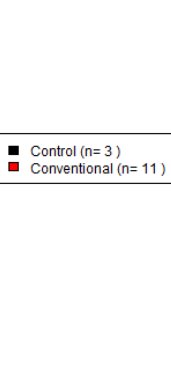

Control $(n=2)$
Conventional $(n=11)$ 


\section{Trip 3}

\begin{tabular}{|c|c|c|c|c|c|c|c|c|c|c|c|}
\hline Trip & Vessel & Year & Month & Week & $\begin{array}{c}\text { Air } \\
\text { temperatur } \\
e\left({ }^{\circ} \mathrm{C}\right) \\
\end{array}$ & $\begin{array}{c}\text { Water } \\
\text { temperatur } \\
e\left({ }^{\circ} \mathrm{C}\right) \\
\end{array}$ & $\begin{array}{c}\text { Wind speed } \\
\text { (Bft) }\end{array}$ & $\begin{array}{c}\text { Wave } \\
\text { height }(\mathrm{m})\end{array}$ & \begin{tabular}{|c|}
$\begin{array}{c}\text { Catch } \\
\text { processing } \\
(\mathrm{min})\end{array}$ \\
\end{tabular} & $\begin{array}{l}\text { Haul } \\
\text { duration } \\
(\min ) \\
\end{array}$ & $\begin{array}{c}\text { Fishing } \\
\text { depth ( } \mathrm{m} \text { ) }\end{array}$ \\
\hline 3 & TX3 & 2017 & June & 24 & $15-20$ & $14-15$ & $1-5$ & $0.1-1.5$ & 20 & $110-125$ & $22-24$ \\
\hline
\end{tabular}

\begin{tabular}{|c|c|c|c|c|c|c|c|c|c|c|c|}
\hline \multicolumn{2}{|c|}{ Plaice } & \multicolumn{2}{|c|}{ Sole } & \multicolumn{2}{|c|}{ Turbot } & \multicolumn{2}{|c|}{ Brill } & \multicolumn{2}{|c|}{ Thornback ray } & \multicolumn{2}{|c|}{ Spotted ray } \\
\hline \# Test & \#Control & \# Test & \#Control & \# Test & \#Control & \# Test & \#Control & \# Test & \#Control & \# Test & \#Control \\
\hline $12 \%$ & $100 \%$ & $40 \%$ & $100 \%$ & $40 \%$ & $100 \%$ & $7 \%$ & $100 \%$ & $63 \%$ & $100 \%$ & - & - \\
\hline
\end{tabular}
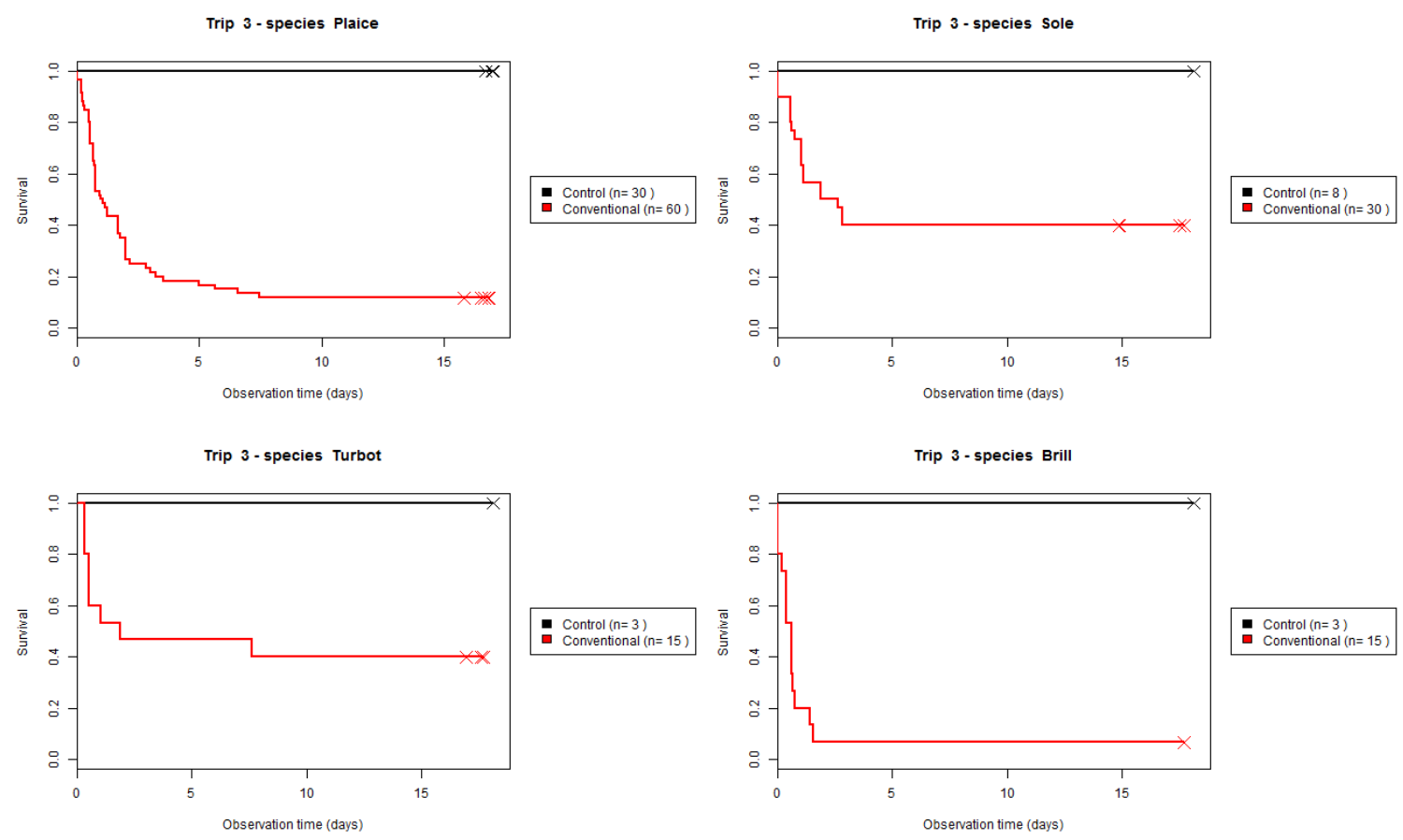

Trip 3 - species Thornback ray

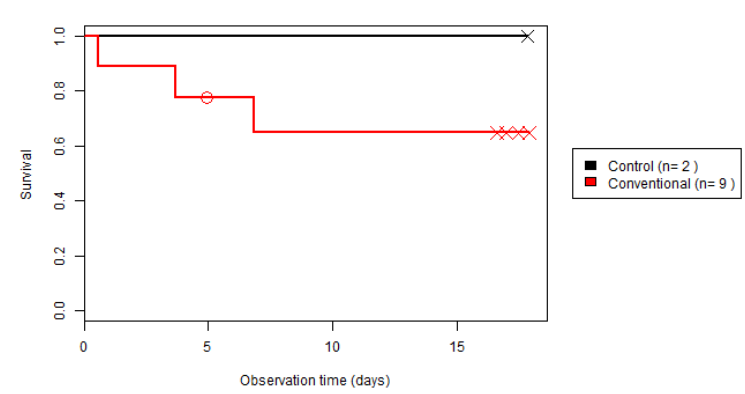




\section{Trip 4}

\begin{tabular}{|c|c|c|c|c|c|c|c|c|c|c|c|}
\hline Trip & Vessel & Year & Month & Week & $\begin{array}{c}\text { Air } \\
\text { temperatur } \\
\mathrm{e}\left({ }^{\circ} \mathrm{C}\right)\end{array}$ & $\begin{array}{c}\text { Water } \\
\text { temperatur } \\
\mathrm{e}\left({ }^{\circ} \mathrm{C}\right)\end{array}$ & $\begin{array}{c}\text { Wind speed } \\
(\mathrm{Bft})\end{array}$ & $\begin{array}{c}\text { Wave } \\
\text { height }(\mathrm{m})\end{array}$ & $\begin{array}{c}\text { Catch } \\
\text { processing } \\
(\mathrm{min})\end{array}$ & $\begin{array}{c}\text { Haul } \\
\text { duration } \\
(\mathrm{min})\end{array}$ & $\begin{array}{c}\text { Fishing } \\
\text { depth }(\mathrm{m})\end{array}$ \\
\hline 4 & TX3 & 2017 & July & 28 & $15-21$ & $16-17$ & $1-6$ & $0.1-1.0$ & 23 & $110-120$ & $25-40$ \\
\hline
\end{tabular}

\begin{tabular}{|c|c|c|c|c|c|c|c|c|c|c|c|}
\hline \multicolumn{2}{|c|}{ Plaice } & \multicolumn{2}{c|}{ Sole } & \multicolumn{3}{c|}{ Turbot } & \multicolumn{3}{c|}{ Thornback ray } & \multicolumn{2}{c|}{ Spotted ray } \\
\hline \# Test & \#Control & \# Test & \#Control & \# Test & \#Control & \# Test & \#Control & \# Test & \#Control & \# Test & \#Control \\
\hline $\mathbf{3 \%}$ & $90 \%$ & $\mathbf{2 3} \%$ & $100 \%$ & $\mathbf{6 3} \%$ & $100 \%$ & $\mathbf{0} \%$ & $100 \%$ & $\mathbf{5 6} \%$ & $100 \%$ & - & - \\
\hline
\end{tabular}

Trip 4 - species Plaice

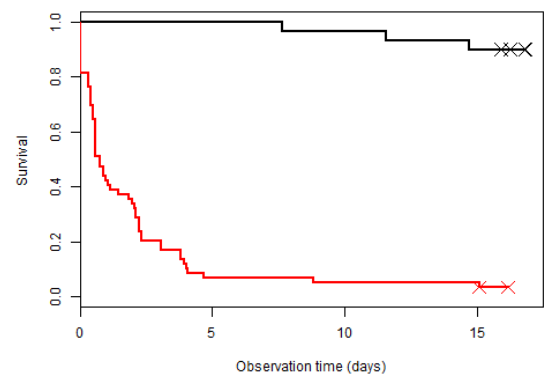

Trip 4 - species Turbot
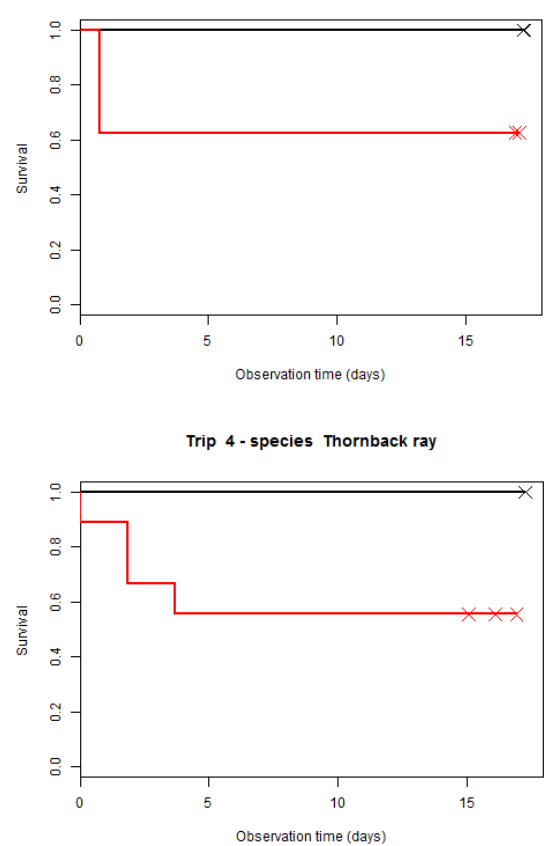

Trip 4 - species Sole

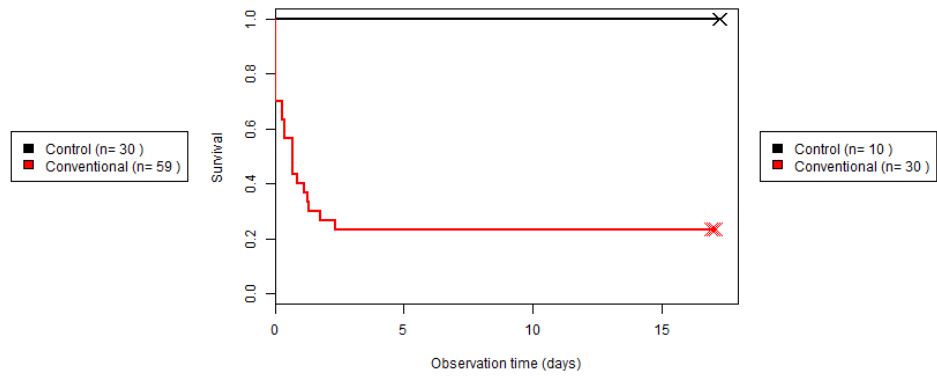

Trip 4 - species Brill

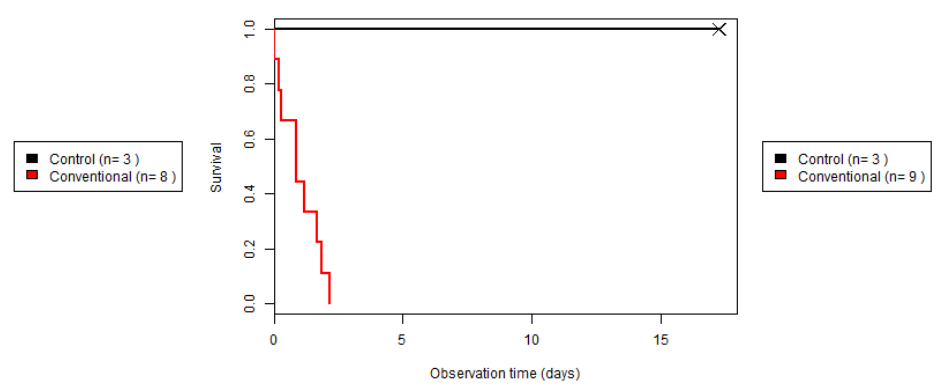

- Control (n=2)
Conventional $(n=9)$ 


\section{Trip 5}

\begin{tabular}{|c|c|c|c|c|c|c|c|c|c|c|c|}
\hline Trip & Vessel & Year & Month & Week & \begin{tabular}{|c} 
Air \\
temperatur \\
$e\left({ }^{\circ} \mathrm{C}\right)$ \\
\end{tabular} & $\begin{array}{c}\text { Water } \\
\text { temperatur } \\
\mathrm{e}\left({ }^{\circ} \mathrm{C}\right)\end{array}$ & $\begin{array}{c}\text { Wind speed } \\
\text { (Bft) }\end{array}$ & $\begin{array}{c}\text { Wave } \\
\text { height }(\mathrm{m})\end{array}$ & $\begin{array}{c}\text { Catch } \\
\text { processing } \\
(\mathrm{min}) \\
\end{array}$ & $\begin{array}{c}\text { Haul } \\
\text { duration } \\
(\text { min) } \\
\end{array}$ & $\begin{array}{c}\text { Fishing } \\
\text { depth ( } \mathrm{m} \text { ) }\end{array}$ \\
\hline 5 & UK33 & 2017 & Sept & 36 & $15-18$ & 18 & $4-5$ & $0.5-1.5$ & 26 & $120-145$ & $26-37$ \\
\hline
\end{tabular}

\begin{tabular}{|c|c|c|c|c|c|c|c|c|c|c|c|}
\hline \multicolumn{2}{|c|}{ Plaice } & \multicolumn{2}{|c|}{ Sole } & \multicolumn{2}{|c|}{ Turbot } & \multicolumn{2}{|c|}{ Brill } & \multicolumn{2}{|c|}{ Thornback ray } & \multicolumn{2}{|c|}{ Spotted ray } \\
\hline \# Test & \#Control & \# Test & \#Control & \# Test & \#Control & \# Test & \#Control & \# Test & \#Control & \# Test & \#Control \\
\hline $1 \%$ & $30 \%$ & $3 \%$ & $90 \%$ & $17 \%$ & $100 \%$ & $0 \%$ & $100 \%$ & $57 \%$ & $100 \%$ & - & - \\
\hline
\end{tabular}

Trip 5 - species Plaice

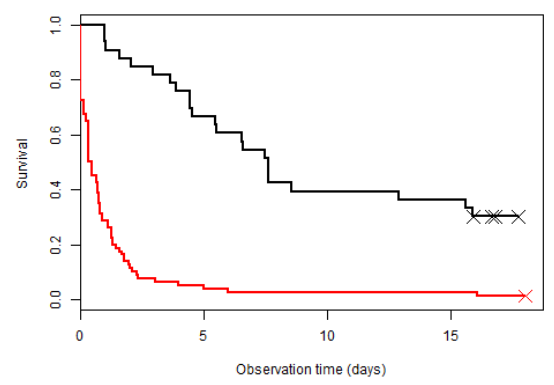

Trip 5 - species Turbot

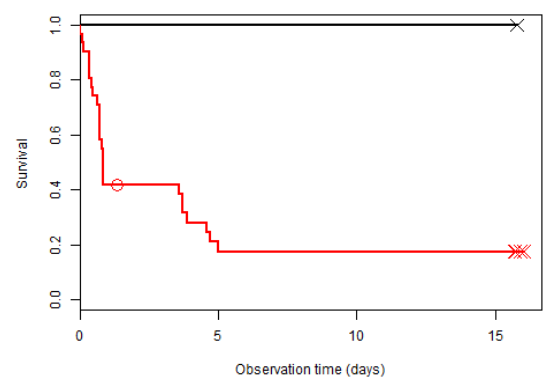

Trip 5 - species Thornback ray

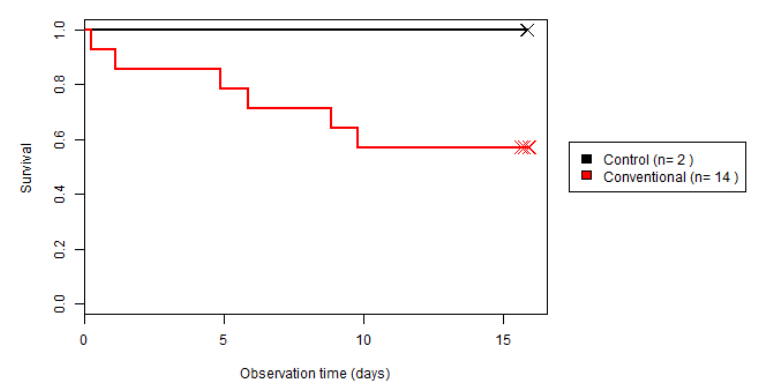

Trip 5 - species Sole

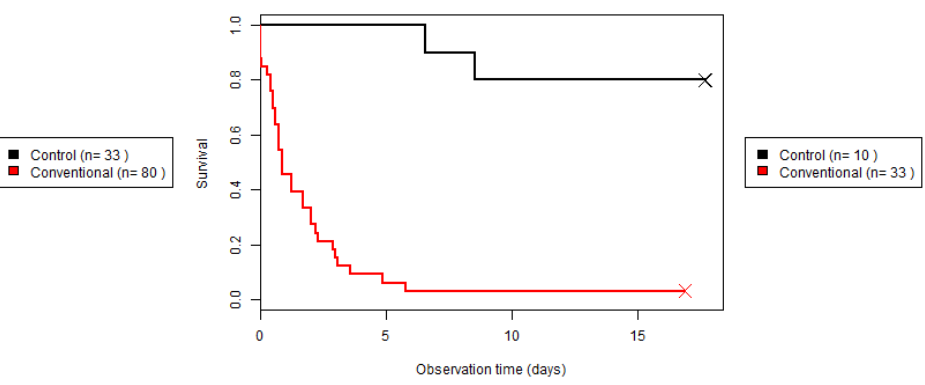

Trip 5 - species Brill

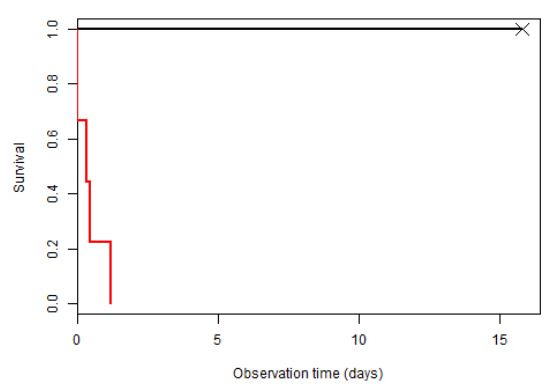

- Control $(n=3)$
Conventional $(n=9)$

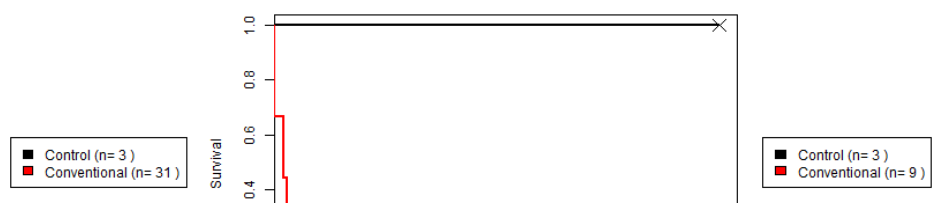




\section{Trip 6}

\begin{tabular}{|c|c|c|c|c|c|c|c|c|c|c|c|}
\hline Trip & Vessel & Year & Month & Week & \begin{tabular}{|c|} 
Air \\
temperatur \\
$e\left({ }^{\circ} \mathrm{C}\right)$ \\
\end{tabular} & $\begin{array}{c}\text { Water } \\
\text { temperatur } \\
e\left({ }^{\circ} \mathrm{C}\right)\end{array}$ & $\left|\begin{array}{c}\text { Wind speed } \\
\text { (Bft) }\end{array}\right|$ & $\begin{array}{c}\text { Wave } \\
\text { height }(\mathrm{m})\end{array}$ & \begin{tabular}{|c|c|c|} 
Catch \\
processing \\
$(\mathrm{min})$ \\
\end{tabular} & $\begin{array}{c}\text { Haul } \\
\text { duration } \\
(\min ) \\
\end{array}$ & $\begin{array}{l}\text { Fishing } \\
\text { depth ( } \mathrm{m} \text { ) }\end{array}$ \\
\hline 6 & TX3 & 2017 & Oct & 44 & $12-15$ & $13-15$ & $3-5$ & $0.5-2.0$ & 20 & $110-130$ & $27-34$ \\
\hline
\end{tabular}

\begin{tabular}{|c|c|c|c|c|c|c|c|c|c|c|c|}
\hline \multicolumn{2}{|c|}{ Plaice } & \multicolumn{2}{|c|}{ Sole } & \multicolumn{2}{|c|}{ Turbot } & \multicolumn{2}{|c|}{ Brill } & \multicolumn{2}{|c|}{ Thornback ray } & \multicolumn{2}{|c|}{ Spotted ray } \\
\hline \# Test & \#Control & \# Test & \#Control & \# Test & \#Control & \# Test & \#Control & \# Test & \#Control & \# Test & \#Control \\
\hline $22 \%$ & $100 \%$ & $10 \%$ & $100 \%$ & $33 \%$ & $100 \%$ & $33 \%$ & $100 \%$ & $79 \%$ & $100 \%$ & - & - \\
\hline
\end{tabular}

Trip 6 - species Plaice

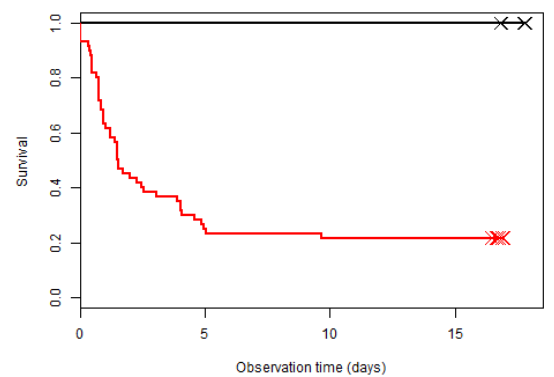

Trip 6 - species Turbot

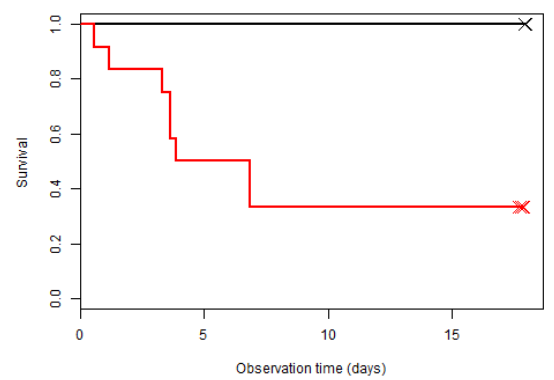

Trip 6 - species Thornback ray

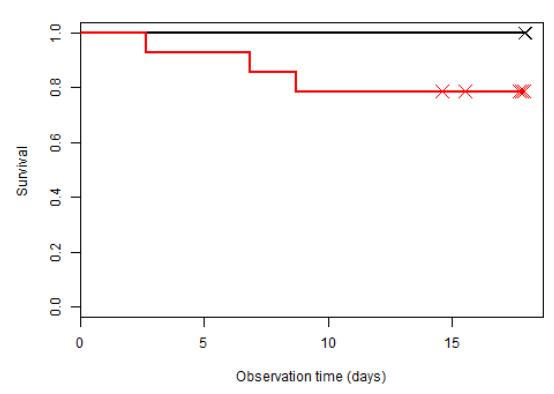

Trip 6 - species Sole

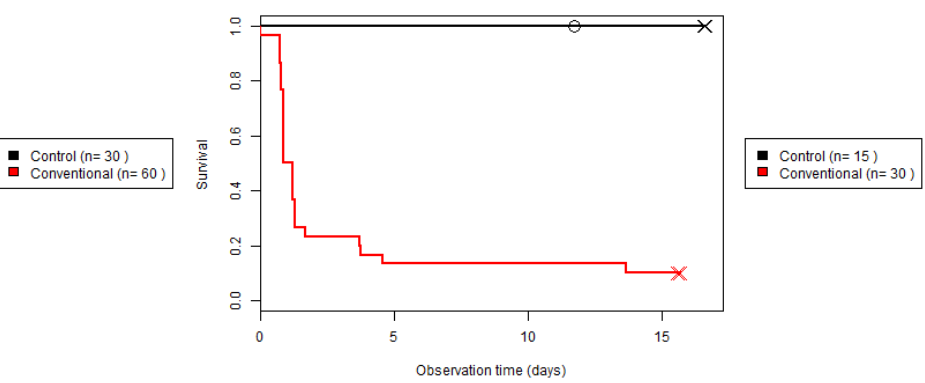

Trip 6 - species Brill

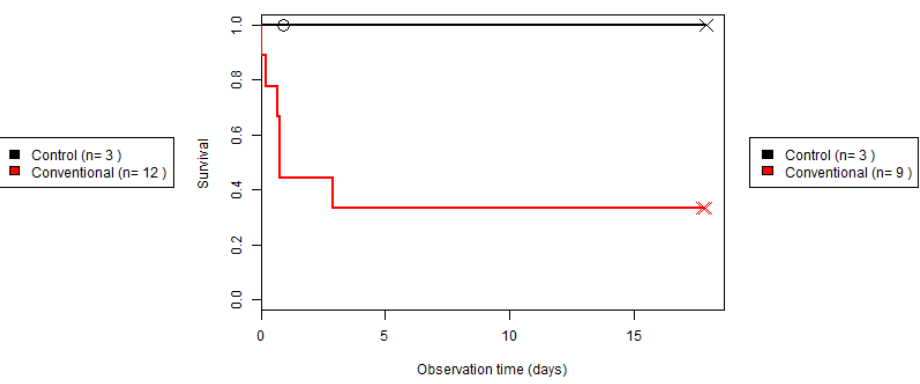

- Control $(n=3)$

- Control $(n=2)$
Conventional $(n=14)$ 
Trip 7

\begin{tabular}{|c|c|c|c|c|c|c|c|c|c|c|c|}
\hline Trip & Vessel & Year & Month & Week & $\begin{array}{c}\text { Air } \\
\text { temperatur } \\
\mathrm{e}\left({ }^{\circ} \mathrm{C}\right)\end{array}$ & $\begin{array}{c}\text { Water } \\
\text { temperatur } \\
\mathrm{e}\left({ }^{\circ} \mathrm{C}\right)\end{array}$ & $\begin{array}{c}\text { Wind speed } \\
(\mathrm{Bft})\end{array}$ & $\begin{array}{c}\text { Wave } \\
\text { height }(\mathrm{m})\end{array}$ & $\begin{array}{c}\text { Catch } \\
\text { processing } \\
(\mathrm{min})\end{array}$ & $\begin{array}{c}\text { Haul } \\
\text { duration } \\
(\mathrm{min})\end{array}$ & $\begin{array}{c}\text { Fishing } \\
\text { depth }(\mathrm{m})\end{array}$ \\
\hline 7 & GO23 & 2017 & Dec & 49 & $5-9$ & $11-12$ & $3-5$ & $1.0-2.0$ & 34 & 120 & $35-50$ \\
\hline
\end{tabular}

\begin{tabular}{|c|c|c|c|c|c|c|c|c|c|c|c|}
\hline \multicolumn{2}{|c|}{ Plaice } & \multicolumn{2}{c|}{ Sole } & \multicolumn{2}{c|}{ Turbot } & \multicolumn{3}{c|}{ Thornback ray } & \multicolumn{2}{c|}{ Spotted ray } \\
\hline \# Test & \#Control & \# Test & \#Control & \# Test & \#Control & \# Test & \#Control & \# Test & \#Control & \# Test & \#Control \\
\hline $\mathbf{2 0} \%$ & $72 \%$ & $\mathbf{0} \%$ & $100 \%$ & $\mathbf{2 2} \%$ & $100 \%$ & $\mathbf{0} \%$ & $100 \%$ & $\mathbf{4 4 \%}$ & $100 \%$ & - & - \\
\hline
\end{tabular}
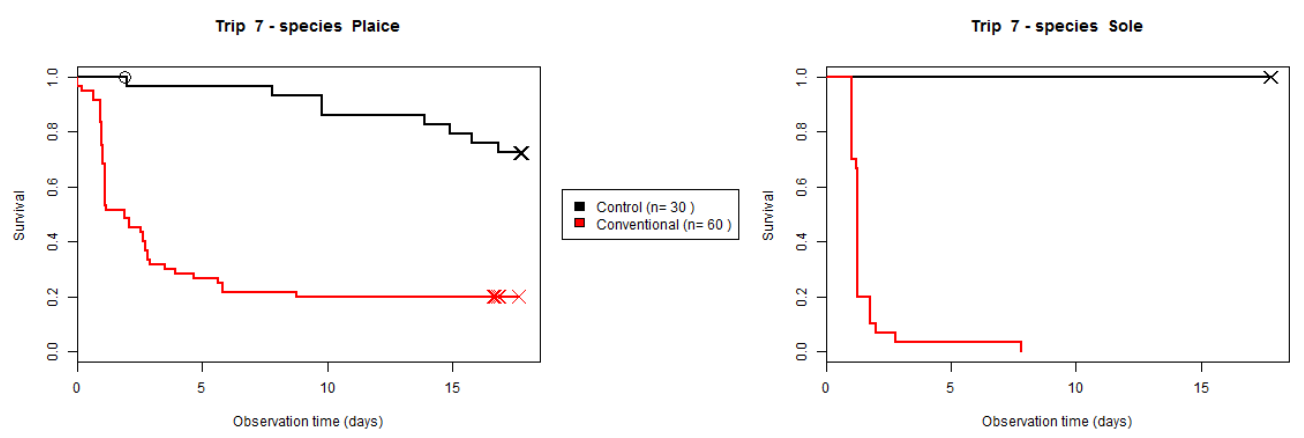

- Control $(n=15)$
Conventional $(n=30)$

Trip 7 - species Turbot
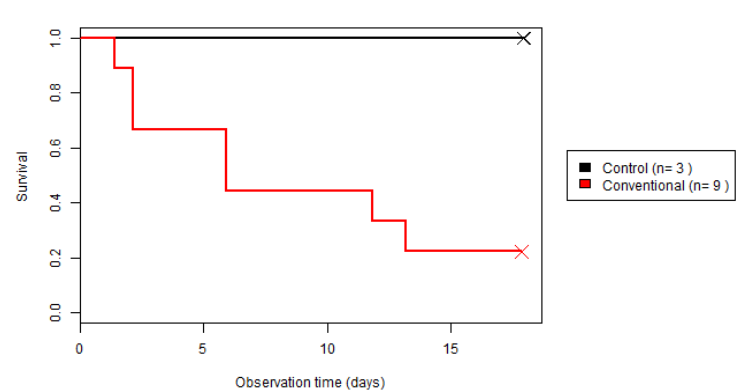

Trip 7 - species Brill
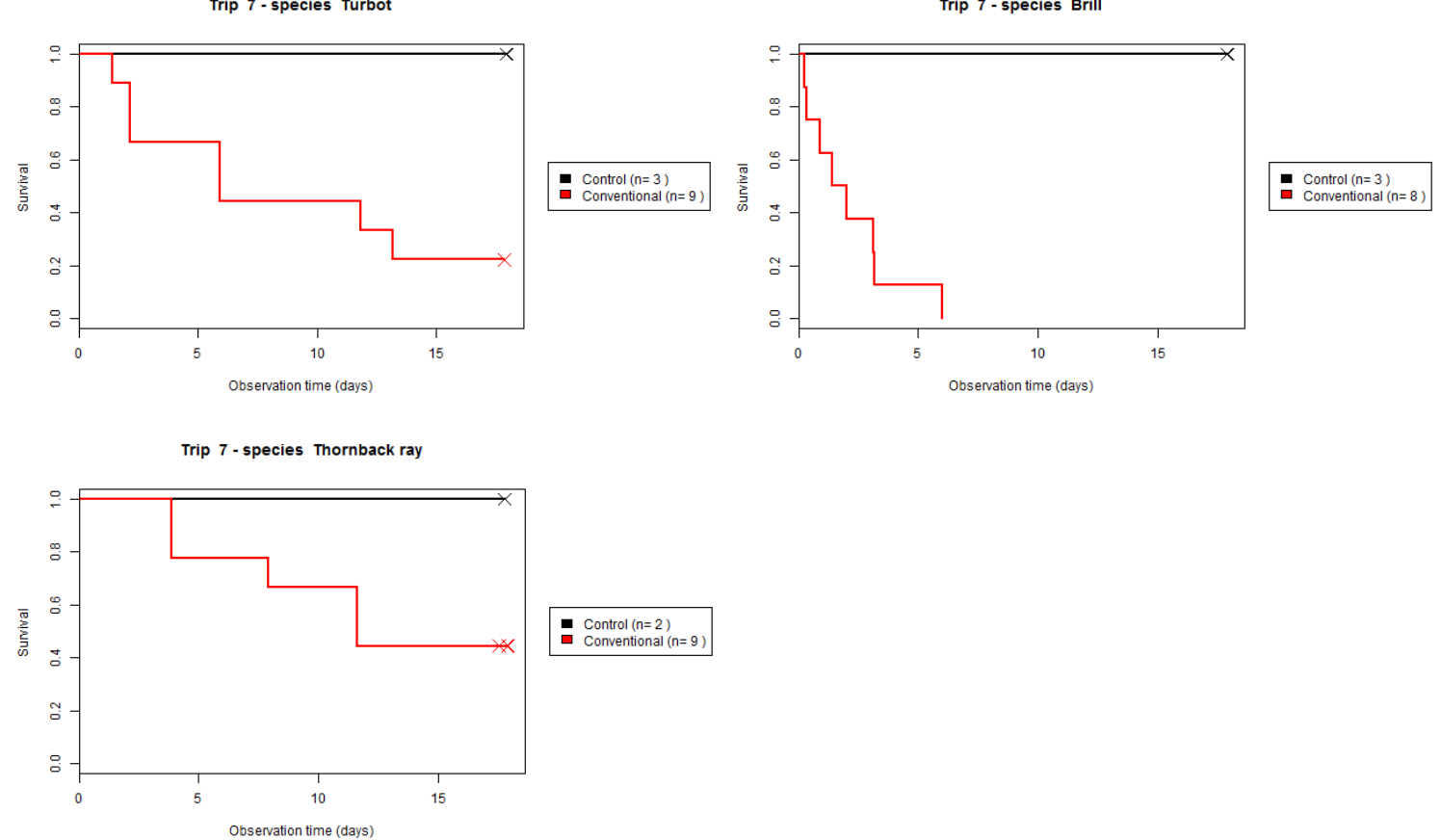


\section{Trip 8}

\begin{tabular}{|c|c|c|c|c|c|c|c|c|c|c|}
\hline Trip & Vessel & Year & Month & Week & $\begin{array}{c}\text { Air } \\
\text { temperatur } \\
e\left({ }^{\circ} \mathrm{C}\right)\end{array}$ & $\begin{array}{c}\text { Water } \\
\text { temperatur } \\
e\left({ }^{\circ} \mathrm{C}\right)\end{array}$ & $\begin{array}{c}\text { Wind speed } \\
\text { (Bft) }\end{array}$ & $\begin{array}{c}\text { Wave } \\
\text { height (m) }\end{array}$ & $\begin{array}{c}\text { Catch } \\
\text { processing } \\
\text { depth }(\mathrm{m})\end{array}$ & $\begin{array}{c}\text { Haul } \\
\text { duration } \\
(\mathrm{min})\end{array}$ \\
\hline 8 & UK33 & 2018 & Jan & 4 & $7-10$ & $6-7$ & $5-6$ & $0.5-2.6$ & 33 & 120 \\
\hline
\end{tabular}

\begin{tabular}{|c|c|c|c|c|c|c|c|c|c|c|c|}
\hline \multicolumn{2}{|c|}{ Plaice } & \multicolumn{2}{|c|}{ Sole } & \multicolumn{2}{|c|}{ Turbot } & \multicolumn{2}{|c|}{ Brill } & \multicolumn{2}{|c|}{ Thornback ray } & \multicolumn{2}{|c|}{ Spotted ray } \\
\hline \# Test & \#Control & \# Test & \#Control & \# Test & \#Control & \# Test & \#Control & \# Test & \#Control & \# Test & \#Control \\
\hline $17 \%$ & $72 \%$ & $0 \%$ & $100 \%$ & $0 \%$ & $100 \%$ & $10 \%$ & $67 \%$ & $0 \%$ & $50 \%$ & $21 \%$ & $100 \%$ \\
\hline
\end{tabular}
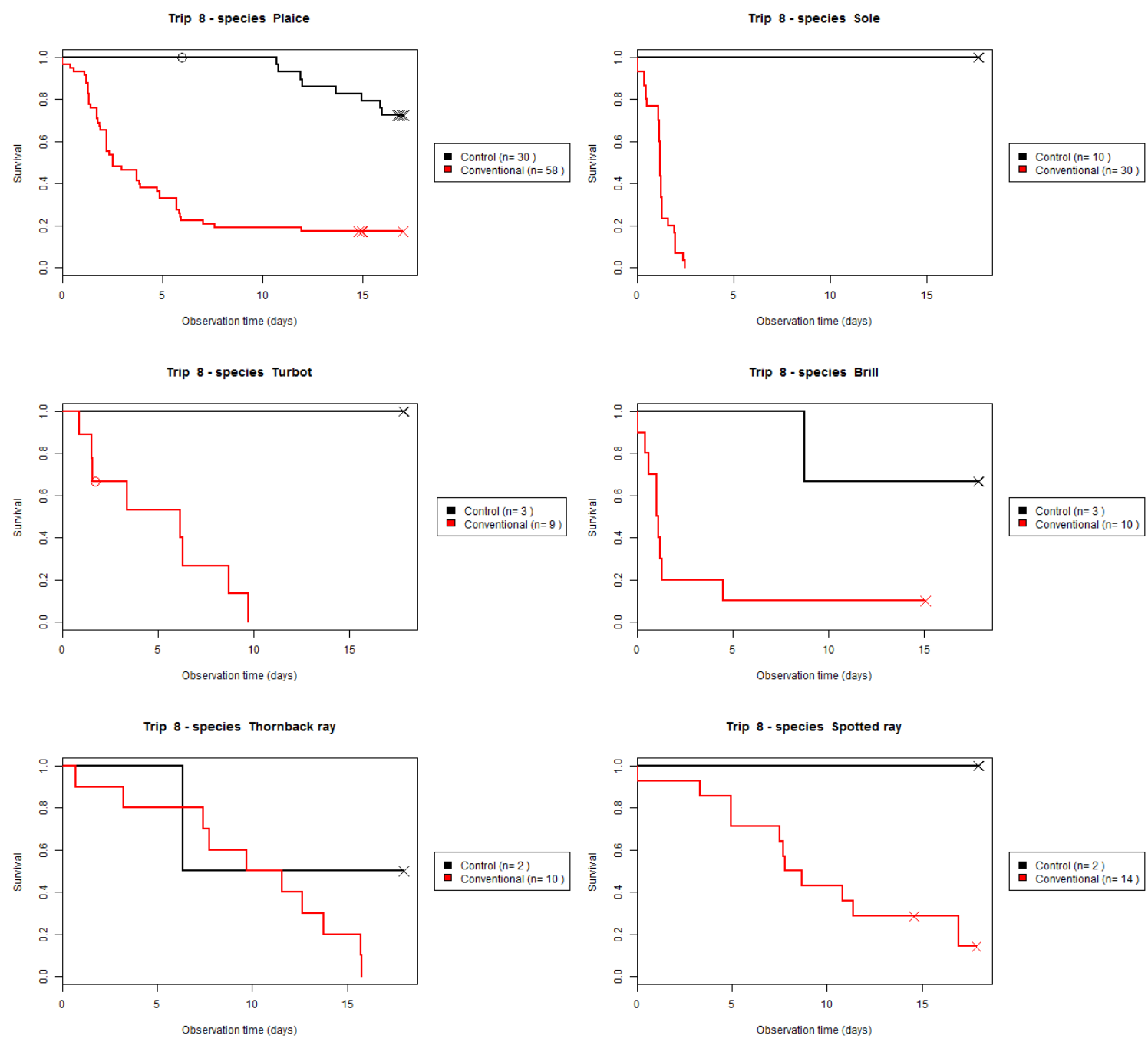


\section{Trip 9}

\begin{tabular}{|c|c|c|c|c|c|c|c|c|c|c|c|}
\hline Trip & Vessel & Year & Month & Week & $\begin{array}{c}\text { Air } \\
\text { temperatur } \\
\mathrm{e}\left({ }^{\circ} \mathrm{C}\right)\end{array}$ & $\begin{array}{c}\text { Water } \\
\text { temperatur } \\
\mathrm{e}\left({ }^{\circ} \mathrm{C}\right)\end{array}$ & $\begin{array}{c}\text { Wind speed } \\
(\mathrm{Bft})\end{array}$ & $\begin{array}{c}\text { Wave } \\
\text { height }(\mathrm{m})\end{array}$ & $\begin{array}{c}\text { Catch } \\
\text { processing } \\
(\mathrm{min})\end{array}$ & $\begin{array}{c}\text { Haul } \\
\text { duration } \\
(\mathrm{min})\end{array}$ & $\begin{array}{c}\text { Fishing } \\
\text { depth }(\mathrm{m})\end{array}$ \\
\hline 9 & $\mathrm{GO} 23$ & 2018 & $\mathrm{Feb}$ & 8 & $4-8$ & $7-8$ & $2-5$ & $0.5-1.5$ & 25 & $110-120$ & $22-52$ \\
\hline
\end{tabular}

\begin{tabular}{|c|c|c|c|c|c|c|c|c|c|c|c|}
\hline \multicolumn{2}{|c|}{ Plaice } & \multicolumn{2}{|c|}{ Sole } & \multicolumn{2}{|c|}{ Turbot } & \multicolumn{2}{|c|}{ Brill } & \multicolumn{2}{|c|}{ Thornback ray } & \multicolumn{2}{|c|}{ Spotted ray } \\
\hline \# Test & \#Control & \# Test & \#Control & \# Test & \#Control & \# Test & \#Control & \# Test & \#Control & \# Test & \#Control \\
\hline $20 \%$ & $93 \%$ & $3 \%$ & $100 \%$ & $0 \%$ & $100 \%$ & $11 \%$ & $67 \%$ & $56 \%$ & $100 \%$ & $67 \%$ & $100 \%$ \\
\hline
\end{tabular}

Trip 9 - species Turbot

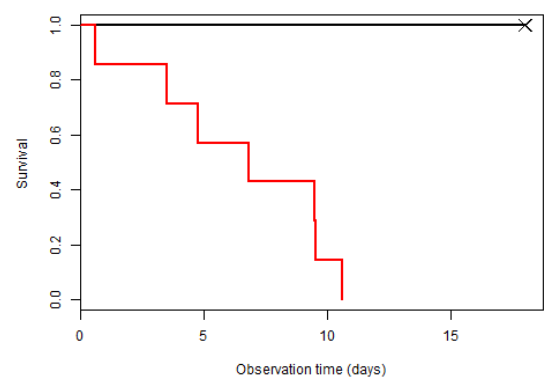

Trip 9 - species Plaice

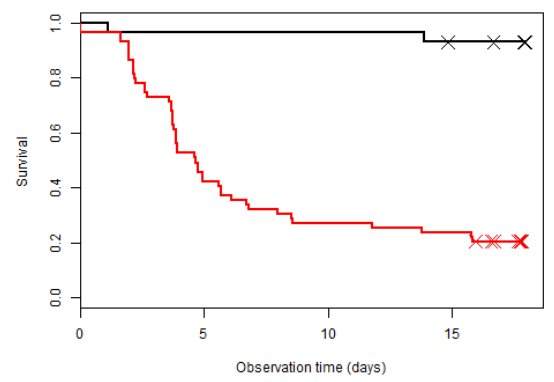

Trip 9 - species Spotted ray

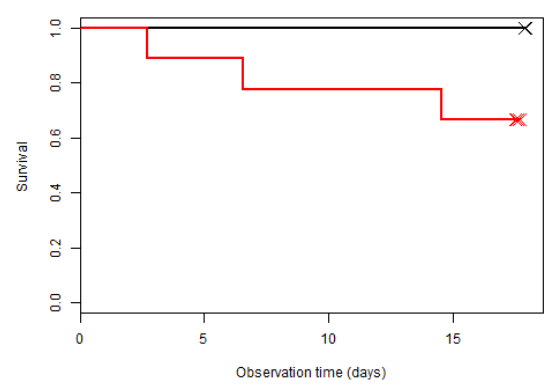

Trip 9 - species Brill

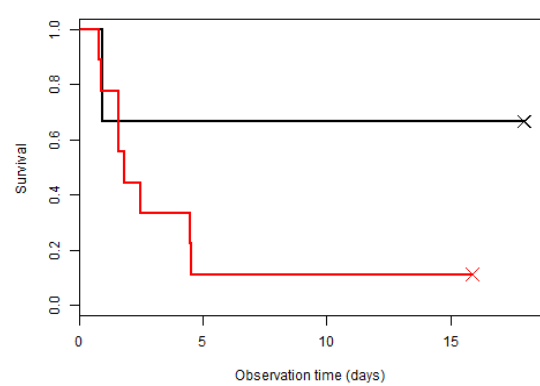

Control $(n=3)$
Conventional $(n=9)$

- Control $(n=3)$
Conventional $(n=7)$

Trip 9 - species sole

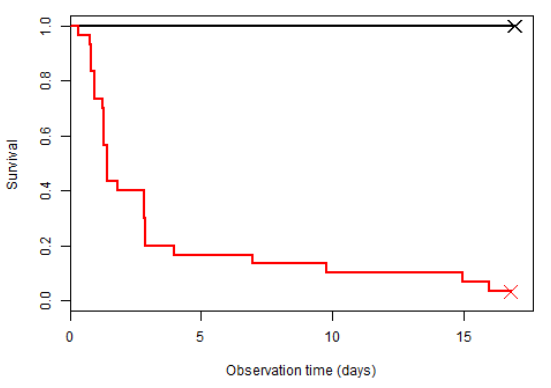

- Control $(n=10)$
Conventional $(n=30)$

- Control $(n=29)$
Conventional $(n=59)$

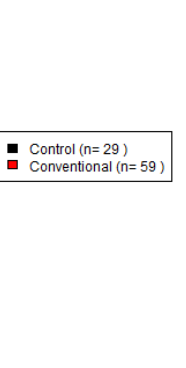

Trip 9 - species Thornback ray

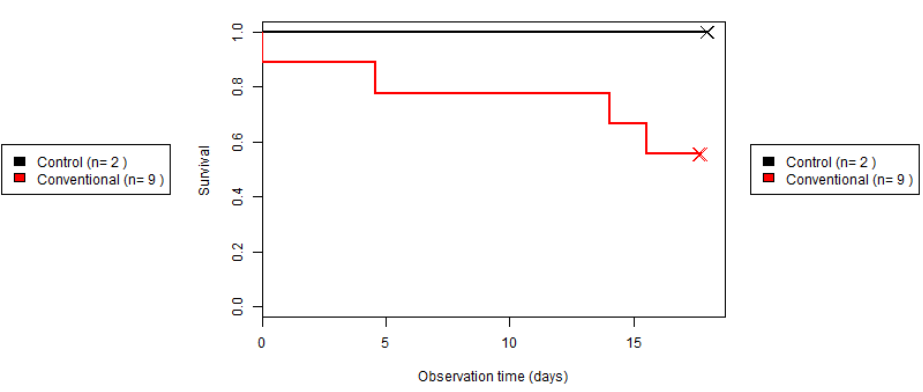




\section{Annex 2: Frequency of vitality index scores per species and trip}

\begin{tabular}{|c|c|c|c|c|c|c|c|c|c|c|c|c|c|c|c|c|c|c|c|c|c|c|c|c|}
\hline \multirow[t]{2}{*}{ Trip } & \multicolumn{4}{|c|}{ Plaice } & \multicolumn{4}{|c|}{ Sole } & \multicolumn{4}{|c|}{ Turbot } & \multicolumn{4}{|c|}{ Brill } & \multicolumn{4}{|c|}{ Thornback ray } & \multicolumn{4}{|c|}{ Spotted ray } \\
\hline & A & B & C & $\mathrm{D}$ & A & $\mathrm{B}$ & C & D & A & B & C & $\mathrm{D}$ & A & $\mathrm{B}$ & $\mathrm{C}$ & D & A & $\mathrm{B}$ & C & $\mathrm{D}$ & A & $\mathrm{B}$ & c & D \\
\hline 1 & 10 & 21 & 17 & 12 & 6 & 11 & 6 & 8 & 2 & 4 & 3 & 0 & 4 & 3 & 2 & 0 & 1 & 5 & 3 & 1 & 0 & 0 & 0 & 0 \\
\hline 3 & 1 & 13 & 35 & 11 & 2 & 12 & 9 & 7 & 2 & 8 & 4 & 1 & 0 & 3 & 7 & 5 & 1 & 3 & 4 & 1 & 0 & 0 & 0 & 0 \\
\hline 4 & 5 & 13 & 13 & 26 & 4 & 4 & 8 & 14 & 3 & 5 & 0 & 0 & 1 & 3 & 3 & 2 & 3 & 4 & 0 & 2 & 0 & 0 & 0 & 0 \\
\hline 5 & 2 & 29 & 20 & 29 & 1 & 11 & 17 & 4 & 9 & 11 & 8 & 3 & 0 & 2 & 0 & 7 & 1 & 6 & 5 & 2 & 0 & 0 & 0 & 0 \\
\hline 7 & 1 & 21 & 23 & 15 & 0 & 7 & 17 & 6 & 5 & 4 & 0 & 0 & 0 & 3 & 4 & 1 & 0 & 5 & 4 & 0 & 0 & 0 & 0 & 0 \\
\hline 8 & 6 & 22 & 16 & 15 & 3 & 8 & 8 & 11 & 7 & 1 & 1 & 0 & 1 & 0 & 0 & 9 & 0 & 3 & 5 & 2 & 2 & 4 & 5 & 2 \\
\hline 9 & 2 & 7 & 11 & 39 & 1 & 5 & 6 & 18 & 1 & 3 & 2 & 1 & 0 & 2 & 0 & 7 & 1 & 2 & 3 & 3 & 3 & 4 & 0 & 2 \\
\hline Total & 40 & 159 & 167 & 189 & 27 & 76 & 93 & 78 & 39 & 46 & 20 & 6 & 7 & 23 & 21 & 39 & 12 & 38 & 33 & 12 & 5 & 8 & 5 & 4 \\
\hline
\end{tabular}


Wageningen Marine Research

T +31 (0)317480900

E: marine-research@wur.nl

www.wur.eu/marine-research

Visitors' address

- Ankerpark 271781 AG Den Helder

- Korringaweg 7, 4401 NT Yerseke

- Haringkade 1, 1976 CP IJ muiden
Wageningen Marine Research is the Netherlands research institute established to provide the scientific support that is essential for developing policies and innovation in respect of the marine environment, fishery activities, aquaculture and the maritime sector.

\section{Wageningen University \& Research:}

is specialised in the domain of healthy food and living environment.

\section{The Wageningen Marine Research vision}

'To explore the potential of marine nature to improve the quality of life'

\section{The Wageningen Marine Research mission}

- To conduct research with the aim of acquiring knowledge and offering advice on the sustainable management and use of marine and coastal areas.

- Wageningen Marine Research is an independent, leading scientific research institute

Wageningen Marine Research is part of the international knowledge organisation Wageningen UR (University \& Research centre). Within Wageningen UR, nine specialised research institutes of the Stichting Wageningen Research Foundation have joined forces with Wageningen University to help answer the most important questions in the domain of healthy food and living environment. 